\title{
PREDICTORS OF POSTSECONDARY SUCCESS FOR STUDENTS WITH AUTISM SPECTRUM DISORDER
}

A Dissertation
presented to
the Faculty of the Graduate School
at the University of Missouri-Columbia
In Partial Fulfillment
of the Requirements for the Degree
Doctor of Education
SARAH E. KIMMEL Paul Watkins, Dissertation Supervisor
MAY 2018


(C) Copyright by Sarah E. Kimmel 2018

All Rights Reserved 
The undersigned, appointed by the dean of the Graduate School, have examined the dissertation entitled:

PREDICTORS OF POSTSECONDARY SUCCESS FOR STUDENTS WITH AUTISM SPECTRUM DISORDER

presented by Sarah E. Kimmel, a candidate for the degree of Doctor of Education and hereby certify that, in their opinion, it is worthy of acceptance.

Dr. Paul Watkins, Committee Chair

Dr. Lisa Bertrand

Dr. Bret Cormier

Dr. David Stader

Dr. Janice Ward 


\section{Dedication}

To Michael, for his endless patience, unwavering support and encouragement, and for consistently pushing me to do and be better. I would not be where I am in this life without you.

To my parents, Jerry and Sheila Kimmel, thank you for teaching me the value of hard work and always believing that I am capable of anything. Most of all, thank you for your patience, love, and support throughout the years. 


\section{Acknowledgements}

To Dr. Paul Watkins, for his patience, feedback, and support throughout coursework and the research process. To all Cohort 10 instructors, thank you for making each summer a unique and meaningful learning experience.

To the members of my dissertation committee, Dr. Paul Watkins, Dr. Lisa Bertrand, Dr. Bret Cormier, Dr. David Stader, and Dr. Janice Ward, thank you for your time and guidance throughout the dissertation process.

To my coworker and statistical guide, Dr. Matthew Traughber, thank you for your encouragement throughout the research process. Your support is truly appreciated.

Finally, to the North Southeast Cohort, thank you for always lending a sympathetic ear and finding a way to make me laugh. Your friendships are the best thing I could ever hope to gain from this program. 


\section{Table of Contents}

Acknowledgements...............................................................

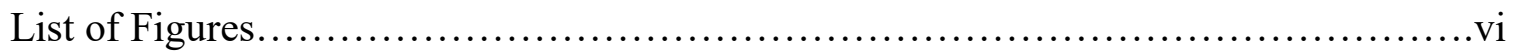

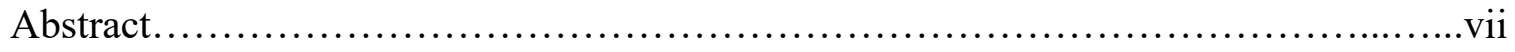

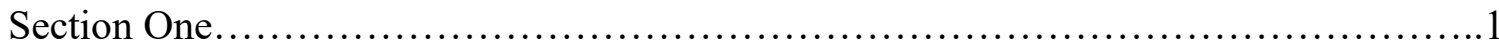

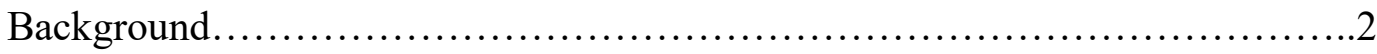

Statement of the Problem.............................................................

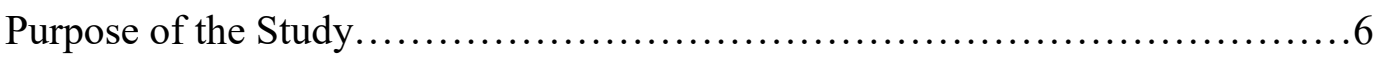

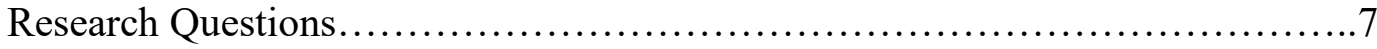

Conceptual Framework.................................................... 8

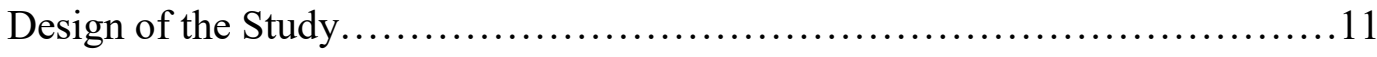

Setting ........................................................... 11

Participants......................................................... 12

Data Collection.......................................................12

Data Analysis.....................................................

Limitations, Assumptions, and Design Controls...............................14

Definition of Key Terms.................................................15

Significance of the Study ...............................................

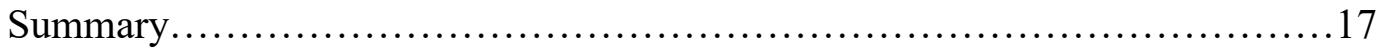

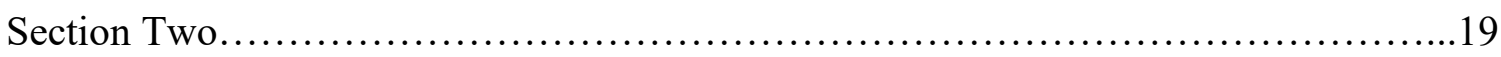

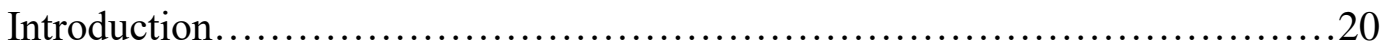

Background of Organization.............................................20

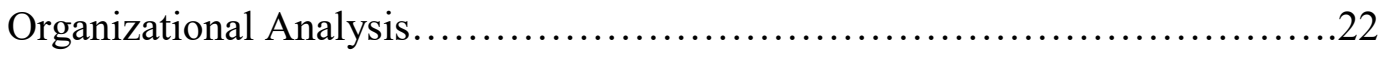


Leadership Analysis...............................................27

Implications for Research............................................... 31

Summary........................................................ 32

Section Three................................................................. 34

Introduction............................................................

Review of Current Scholarship......................................... 38

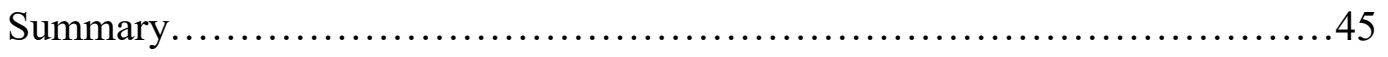

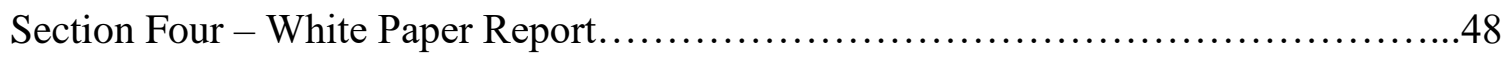

Table of Contents..................................................49

Introduction.......................................................50

Research Process.....................................................50

Factors Impacting Postsecondary Success..............................51

Research Findings..................................................56

Limitations and Recommendations..................................56

Implications for Practice.............................................59

References.......................................................61

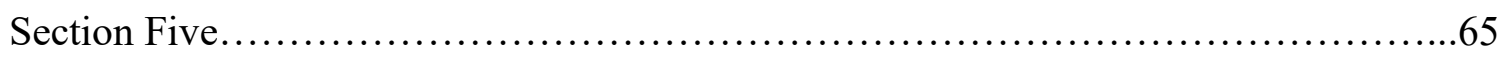

Abstract...........................................................66

Introduction......................................................... 66

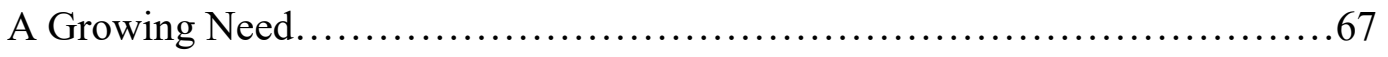

Self-Contained Schools................................................69

The Role of Socioeconomic Status.......................................70

Are Community-Based Work Experiences Helpful?.......................................72 


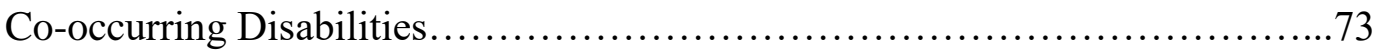

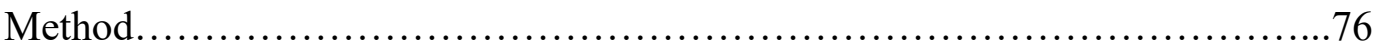

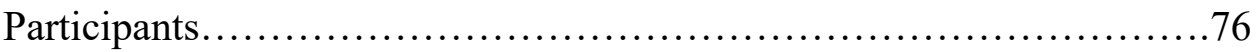

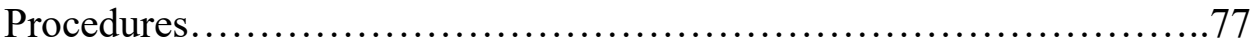

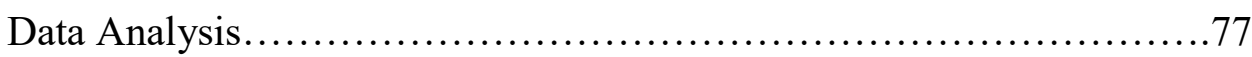

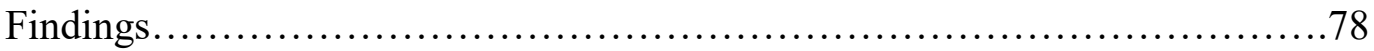

Participation in CBWE.............................................. 78

Low Socioeconomic Status....................................... 78

Multiple Disability Diagnoses........................................ 79

Low SES, Participation in CBWE, Multiple Diagnoses...................79

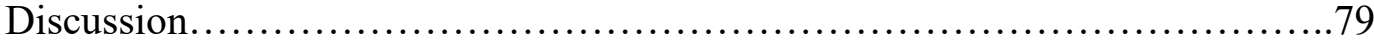

Implications for Practice................................................ 83

Declaration of Conflicting Interests.......................................... 84

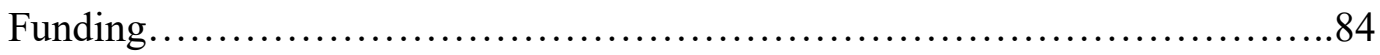

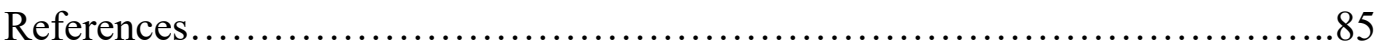

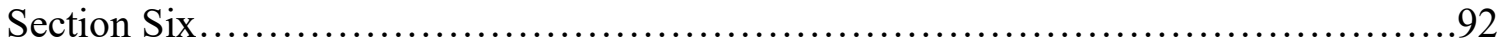

Scholarly Practitioner Reflection............................................... 93

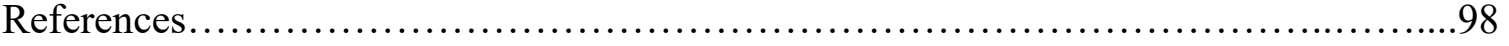

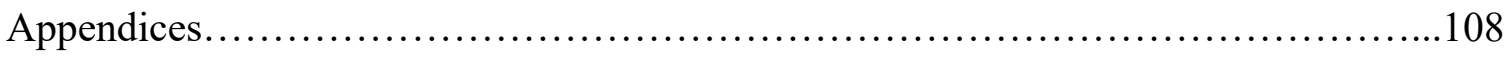

Appendix A - Graduate Six Month Follow Up...............................108

Appendix B - Confirmation of Submission..................................109

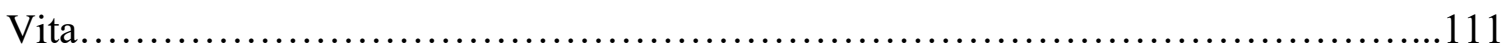




\section{List of Figures}

Figure 1 - Descriptors of Graduates with ASD by Year............................51 
Predictors of Postsecondary Success for Students with Autism Spectrum Disorder

\author{
Sarah E. Kimmel \\ Dr. Paul Watkins, Dissertation Supervisor
}

\begin{abstract}
The purpose of this quantitative study was to analyze the impact of three predicting factors, low socioeconomic status (SES), participation in community based work experience (CBWE) programs, and the presence of multiple disability diagnoses, on postsecondary outcomes of students with Autism Spectrum Disorder (ASD). The case study specifically analyzed postsecondary outcomes of 70 high school students with an educational diagnosis of ASD, who graduated from public, self-contained special education secondary schools during the 2014-2017 academic years. Postsecondary outcomes were measured through data gathered by the school district's Graduate Six Month Follow Up questionnaire.

Study results found no statistically significant impact of any predictor variables on postsecondary outcomes. Results also indicated no significant relationship between the three predictor variables. Limitations of the study include sample size, qualification for free and reduced lunch, data collection tools, and time frames. Implications for practice and future research opportunities are discussed.
\end{abstract}




\section{SECTION ONE:}

INTRODUCTION TO DISSERTATION IN PRACTICE 
Section One: Introduction to Dissertation in Practice

\section{Background}

For over thirty years, the United States has advocated for the success of individuals with disabilities in the workplace, creating and implementing many different initiatives to support and promote employability. Unfortunately, outcomes for these individuals have shown little improvement over time. The United States Department of Labor (2016) reports that $36.8 \%$ of youth with a disability, between the ages of 16 and 19 , were unemployed. Over 17\% of youth with disabilities between the ages of 20 and 24 were unemployed. These numbers may sound low, but compare them with the population of unemployed youth without disabilities. Only $15.8 \%$ of youth between the ages of 16 and 19 reported unemployment. The number decreases further to $8.1 \%$ for youth between the ages of 20 and 24 (United States Department of Labor, 2016). These statistics do not provide detailed information regarding the type and severity of disability of the individuals struggling with employment. For those with disabilities that include deficits in communication and social interactions, post-secondary employment outcomes can differ vastly from other individuals with less severe disabilities.

Post-secondary success looks different for every youth with a disability. The American government continues to focus on policies regarding employment opportunities for youth with disabilities (Fabian, Simonsen, Deschamps, \& Luecking, 2016). In 2014, Congress passed the Workforce Innovation and Opportunity Act (WIOA), a bill whose goal is to update and improve the nation's workforce development system (Education and Workforce Committee of the United States House of Representatives, 2014). The implementation of WIOA in 2015 has placed further stipulations on services and supports 
for youth with disabilities as they enter the workforce (The Arc, 2015). Specifically, regarding individuals with disabilities, WIOA will provide job search, placement assistance, career counseling skills training, and other supportive services for individuals with disabilities (Marquette, 2016). Recently, the Huffington Post (2015) highlighted several major corporations' efforts to recruit and hire adults with disabilities, specifically those with Autism Spectrum Disorder (ASD), as a way to become more inclusive (Erbentraut, 2015). Despite all this perceived support, finding and maintaining employment continues to be a struggle for youth with disabilities (Roux, Shattuck, Cooper, Anderson, Wagner, \& Narendorf, 2013).

Past research has cited many factors impacting employment success for youth with disabilities, such as a lack of employment training, lack of family and community supports, and lack of self-advocacy (Benz, Yovanoff, \& Doren, 1996; Bellman, Burgstahler, \& Ladner, 2014; Gragoudas, 2014; Trainor, Morningstar, \& Murray, 2015; Wehman, Sima, Ketchum, West, Chan, \& Luecking, 2014). For youth with disabilities to achieve successful employment, they must not only have cohesive family and community supports, but extensive opportunities to gain work experience as well (Bellman, et al., 2014; Gragoudas, 2014; Lindstrom, Paskey, Dickinson, Doren, Zane, \& Johnson, 2007; Wehman, et al., 2014). Therefore, special education schools and programs need to begin to build these skills and supports into their curriculum as students near graduation.

\section{Statement of the Problem}

Many of the employment training and transition supports provided to students with disabilities exist in a typical public education environment. That is, students with disabilities are included in the general education curriculum and environment per 
inclusive education guidelines. However, those students with more high needs disabilities, like ASD, require self-contained programs to meet their educational needs. Self-contained programs exist entirely separate from the general education student population and have a specialized curriculum to meet the needs of students with intensive disabilities. A theoretical benefit of self-contained classrooms is their ability to provide high levels of these small group and one-to-one arrangements to meet student need while increasing student engagement (Logan \& Keefe, 1997). However, participating in these self-contained schools or programs can limit or eliminate students' opportunities for experiences in real-life work environments.

Although there is a large body of research regarding what is needed for students with disabilities to be successful as they transition from school to work, a gap in the research literature exists regarding predictors of employment outcomes for the population of students with ASD. While it seems apparent the high school work experiences may benefit students with ASD as they transition to life after high school, there are still many unanswered questions. What additional supports, if any, ensure post-secondary success for students with ASD? What do post-secondary outcomes look like for students with ASD whose needs prevent them from participating in a traditional academic curriculum or school setting? Are students with ASD who participate in self-contained education settings able to obtain employment? This study aims to consider plausible answers for these questions.

The US Department of Education (2011) reports that there are 6,608,446 youths in special education, with $10 \%$ between the ages of 14 and 21 years. As the prevalence of ASD diagnoses increases, a large portion of this population is preparing to enter 
adolescence and young adulthood (Centers for Disease Control, 2012). Many of the evidence-based practices implemented with this population have been focused on children between the ages of three and six years (Schall, Wehman, \& McDonough, 2012).

Furthermore, current research is limited as to the impacts of socioeconomic status (SES) on the employment outcomes of students with ASD. Research often cites family support as an indicator for employment success for those students with ASD (Benz, et al., 1996; Bellman, et al., 2014; Gragoudas, 2014; Trainor, et al., 2015; Wehman, et al., 2014). However, the likelihood of families with children with ASD experiencing financial strain is great (Buescher, Cidav, Knapp, \& Mandell, 2014; Saunders, Tilford, Fussell, Schulz, Casey, \& Kuo, 2015). As a result, families may not be able to provide supports necessary for their child to be successful in obtaining and maintaining employment after graduation.

As research regarding ASD continues, a significant portion of the population of those diagnosed with ASD are also diagnosed with a second disability (Saunders, et al., 2015). With a push from the American government for employment, it is clear that this population will encounter added challenges. As it stands, little research exists on the postsecondary employment rates for those with multiple disabilities, including ASD. Further investigation is needed to determine the needs of this population to establish programs that can adequately support these students after graduation.

It is clear that students with ASD possess the ability to contribute to the workforce in many ways. With the right supports in place, post-secondary success for this student group can increase dramatically. The supports needed to connect this population with 
best fit employment opportunities are relatively unknown. More research is needed on how to provide students with ASD the much-needed work experiences and supports to develop their skills to ensure post-secondary success.

\section{Purpose of the Study}

Currently, little research exists regarding employment outcomes of these students who participate in employment training programs and other transition support while enrolled in self-contained special education schools. However, WIOA's (2014) goals are geared specifically towards either full or part time employment for all individuals with disabilities, including those with the most significant disabilities (Marquette, 2016). In the present study, insight will be provided as to what predictors may signify postsecondary success for students with ASD in the areas of both post-secondary goal attainment and maintenance.

Additionally, current research reports that, for youth with disabilities to be successful in finding and maintaining employment, many outside supports are necessary (Holwerda, van der Klink, de Boer, Groothoff, \& Brouwer, 2013; Saunders, et al., 2015). Financial support is key to ensure that those with ASD receive the services they need to receive continued support after graduation. Past research indicates that those families with children who have ASD often incur financial hardships, making accessing those services difficult (Saunders, et al., 2015). Lack of financial supports often causes added stress to families, much to the detriment of young adults with ASD in their pursuit for employment after graduation (Mayes \& Calhoun, 2011). This study will explore the possible implications of financial strain, as defined by SES, on the employment success of students with ASD. 
Further, research discusses the increasing frequency that ASD is diagnosed along with other disabilities (Saunders, et al., 2015). A secondary disability diagnosis can often result in compounded difficulties for students already facing significant challenges as they transition into the world of work (Saunders, et al., 2015). Research is needed to determine how these co-occurring disabilities impact the ability of students to obtain employment after graduation, as well as what supports may be needed to ensure maintenance of employment once attained.

The current study is relevant to current special education teachers, school counselors, transition facilitators, district administrators, parents, and community agencies. Teachers, along with school counselors and other transition support staff, must not only teach students employment skills, but also instill in students the ability to advocate for themselves as they navigate the employment world with far fewer supports than ever before. District administrators are invested in student outcomes, as they are vital for funding, accreditation, and more. Parents must learn how to navigate a new world for their student outside of school without the assistance of the school after graduation. Community agencies and businesses need qualified workers. Teachers, school support staff, and administrators, whose programs focus on meeting the more intensive needs of special education students, must ensure the success of these students after graduation. This study can help inform key partners and assist in collaborative approaches in designing successful transition programs for those students with ASD.

\section{Research Questions}

This research study will target the following questions related to the post-secondary outcomes of students with an educational diagnosis of Autism Spectrum Disorder. 
1) What is the impact of participation in a Community Based Work Experiences (CBWE) program during high school on post-secondary success as defined by the Graduate Six Month Follow Up questionnaire for students with Autism Spectrum Disorder who attended a self-contained secondary special education school between the academic years of 2013-14, 2014-15, 2015-16, and 2016-17?

2) What is the impact of socioeconomic status (SES), as defined by qualification for Free and Reduced Lunch programs, on postsecondary success as defined by the Graduate Six Month Follow Up questionnaire for students with Autism Spectrum Disorder who attended a self-contained special education secondary school between the academic years of 2013-14, 2014-15, 2015-16, and 2016-17?

3) What is the impact of a secondary disability diagnosis on post-secondary success as defined by the Graduate Six Month Follow Up questionnaire for students with Autism Spectrum Disorder who attended a self-contained secondary special education school between the academic years of 2013-14, 2014-15, 2015-16 and 2016-17?

\section{Conceptual Framework}

Kohler's (1996) conceptual model for transition programming for students with disabilities links transition theory with transition practice. Kohler's (1996) theory is founded on a perspective promotes the idea that programs and instructional activities should be a) based upon student post-secondary goals and b) driven by individual needs, interests, and preferences. Thus, transition planning should be the foundation from which educational programs and activities are developed (Kohler, 1996). Most important, throughout the entire transition process, students should be actively involved in the 
process with their needs as the focus of all programs and activities. 'Individualized planning is the key to matching students' educational program and school experiences to their post-school goals' to foster success in life after high school (Kohler, 1996). To achieve student success after graduation, regarding employment or any other arena, schools and programs must promote activities that focus on the student's individual abilities, needs, and goals (Kohler, 1996). One facet of this model, structured work experiences paired with student participation in individual level planning, has been shown to be effective in preparing students with disabilities for post-secondary transitions (Kohler, 1996).

Persons with ASD display common behavioral characteristics including "communication deficits, social skill deficits, and restricted, repetitive, and stereotyped patterns of activities, interests, and behaviors" (Schall \& McDonough, 2010). Community based vocational learning programs have been shown to increase skills areas that students with ASD typically lack, such as communication, problem solving, and selfconfidence while also promoting motivation, job-related skills, relationship building, and self-advocacy (Bellman, et al., 2014; Kohler, 1996; Wehman, et al., 2014). Participation in employment training in the classroom or school community, active involvement with transition planning, and a demonstrated ability for self-advocacy increases the likelihood that youth with disabilities will be successful in obtaining employment after graduation (Gragoudas, 2014; Kohler, 1996; Owens, 2011; Wehman, et al., 2014). Schools and special education programs can benefit from incorporation of community work skills training programs because these programs have shown to improve the employability of students with disabilities (Wehman, et al., 2014). 
Legislation regarding transition for students with disabilities has always focused on outcomes, activities, student preferences and interests, and stakeholder involvement. (Kohler, 1996). The Individuals with Disabilities Education Act (2004) also emphasizes the need for the development of employment skills along with community experiences to aid in a smooth transition from school to post school activities. Transition services are defined by the IDEA (2004) legislation as follows:

Transition services mean a coordinated set of activities for a student with a disability that:

A. Is designed to be within a results-oriented process that is focused on improving the academic and functional achievement of the student with a disability to facilitate the students' movement from school to post school activities, including: post-secondary education, vocational education, integrated employment, continuing and adult education, adult services, independent living, or community participation.

B. Is based on the individual student's needs, taking into account the student's strengths, preferences, and interests; and

C. Includes instruction, related services, community experiences, the development of employment and other post school adult living objectives, and, if appropriate, acquisition of daily living skills and functional vocational evaluation. (Sec. 300.43, paragraph 1)

IDEA's (2004) standards are significant to this study because they closely align with the goals of many CBWE programs provided in special education schools. IDEA (2004) aims to incorporate programming like CBWE into students' special education 
experience to promote post-secondary success. Focusing on employment skills is a dramatic switch from the previous academic focus of special education programming related to post-secondary success.

Past trends in research have cited academic preparation as an indicator of postsecondary success for students with disabilities, holding tight to the idea that the more rigorous the student's academic coursework during their high school years, the more likely those students with disabilities will be to a) pursue education beyond the high school level and b) disclose their disability and seek out supports. (Newman, Madaus, \& Javitz, 2016). However, as more is learned about ASD and other disabilities, a shift in the research focus is beginning to emerge. Current studies have begun to focus on real-world activities as a means of continuing education while at the same time developing work skills that are easily transferable to the post-secondary world of work, indicating a shift in thinking that participation in work experiences during high school promotes employability of students with disabilities (Bellman, et al., 2014; Gragoudas, 2014;

Owens, 2011; Wehman, et al., 2014).

\section{Design of the Study}

\section{Setting}

This research was conducted using information from a public special education school district in the United States. The school district boundaries cover a large county, over 500 square miles, and is located near a large metropolitan area. The district contracts with all 22 districts within the county to provide special education services to nearly 25,000 students with disabilities. For this specific study, only students who attend the district's three secondary self-contained special education schools will be considered. 
Self-contained schools refer to schools that provide special education services at a separate location for those students whose needs are unable to be met in a typical public school setting with special education supports. Each of these schools incorporates a CBWE program for students ages 18-21 to assist with acquisition of the necessary skills to ensure post-secondary success. Levels of participation vary based on ability and demonstrated support needs. Therefore, not all students attending self-contained schools participate in the CBWE program.

\section{Participants}

For this study, data was collected regarding student who have graduated from self-contained schools, that is those students who are between the ages of 18 and 21 years, with an educational diagnosis of ASD. This study considered data collected regarding these students over the past four academic school years, 2013-14, 2014-15, 20015-16, and 2016-17. For students with an educational ASD diagnosis, the typical high school program lasts between 5 and 7 years, extending until age 21 if deemed appropriate by the students' Individualized Education Program (IEP) team. Following completion of four years of academic high school curriculum, students may participate in a community based work experience program for up to 3 years before graduating.

\section{Data Collection}

All data collected regarding students was electronic and no direct contact was necessary. Information regarding student post-secondary employment outcomes was collected by district employees six months after the student's graduation date using an electronic Graduate Six Month Follow Up questionnaire (Appendix A). The information was then input into secure electronic Microsoft Excel files, accessible only by district 
employees with appropriate permissions. The researcher requested specific data sets from the district's research and evaluation department by submitting a copy of the dissertation proposal and descriptors of the needed data along with the district required application to conduct research and a copy of the approved University of Missouri-Columbia Institutional Review Board application forms. The researcher was provided only the data requested by the district's research and evaluation department. The data requested encompassed all graduates of the three self-contained secondary special education buildings over the following four academic years: 2013-14, 2014-15, 2015-16, and 201617. Data collected included student SES (defined by participation in the free and reduced lunch program), all educational diagnoses of the student, student's participation in a community based work program (per transcript information), and student results of the Graduate Six Month Follow Up questionnaire. To preserve confidentiality, all data was scrubbed of identifying information before it was provided to the researcher. Data collected was be stored on a password protected laptop that, when not in the possession of the researcher, was be stored in a locked office area.

\section{Data Analysis}

Data was analyzed using Pearson's Chi Square test, due to the small sample size. Post-secondary outcomes were compared between two groups of students with ASD those who did participate in CBWE and those who did not. Post-secondary outcomes were also compared between a second grouping of students - those who qualified as low SES students and those who did not. A third comparison of post-secondary outcomes of two student groups also took place between those students with a diagnosis of ASD and 
those students who had multiple disability diagnoses, one of which is ASD. Statistical significance will be set at $\mathrm{p}<.01$.

\section{Limitations, Assumptions, and Design Controls}

One clear limitation of the study was sample size. MCSD has only recently begun to collect post-secondary outcome data electronically. While the district is working to convert paper copy data to an electronic format, only electronic data from the past four academic years was readily accessible. To attempt to obtain a sufficient sample size of at least 30 students, data was collected to include all four of the academic years that have available electronic data, 2013-2017. Data collected included students at all three of the self-contained special education high school sites to ensure the largest sample size possible.

A second limitation may be students' qualification for free and reduced lunch. MCSD is not the district that determines eligibility. The determination comes from the student's home district. However, some districts, due to the SES of the community they serve, automatically qualify all students for free and reduced lunch upon enrollment.

It is important to note that the primary researcher in this study is employed by MCSD in one of the secondary self-contained schools as a transition facilitator. Part of the researcher's employment duties include collecting data for the Graduate Six Month Follow Up questionnaire for graduates of the school at which the researcher is employed. The 2017-18 school year will be the second year the researcher has held this position. The researcher does not anticipate any impact of current employment or position on this research study as the data has been previously collected. 
Additionally, many other factors may impact students' post-secondary outcomes. Some of these factors may include, but are not limited to, family support, community involvement, and student motivation. While important, this study did not focus on the impact of these variables.

Assumptions of the researcher included that participation in the CBWE will increase the post-secondary success of students with ASD. The researcher also assumed that a relationship does exist between student SES and post-secondary employment for students with ASD. Although the severity of each educational diagnosis of ASD may vary, the researcher also assumed that students with a singular diagnosis of ASD may be more likely to achieve their postsecondary goals than those students with multiple disability diagnoses. The researcher is aware that these assumptions may impact or influence this research study and the researcher made every effort to avoid the influence of preconceived assumptions while conducting the research.

\section{Definition of Key Terms}

\section{Autism Spectrum Disorder (ASD)}

Autism Spectrum Disorder (ASD) is defined as a developmental disability significantly affecting verbal or nonverbal communication and social interaction, generally evident before age 3, which adversely affects a child's educational performance. Other characteristics often associated with autism are engagement in repetitive activities and stereotyped movements, resistance to environmental change or change in daily routines, and unusual responses to sensory experiences. (Parent handbook - autism: Resources, definition, \& criteria, 2017).

\section{Community Based Work Experiences (CBWE)}


Community based work experiences (CBWE) are experiences that may include in-school or after school opportunities, or experiences outside the traditional school setting (including internships), that are provided in an integrated environment to the maximum extent possible (Education and Workforce Committee of the United States House of Representatives, 2014).

\section{Individualized Education Program (IEP)}

Individualized Education Programs include the following:

1) A meeting where parents, students when appropriate, and school personnel jointly make decisions about an educational program for a student with a disability.

2) A document; a written record of the decisions reached at the meeting for a student who will receive special education and related services.

3) A management tool in implementing an educational program that includes services and accommodations to meet the specific needs of the student based on their educational diagnosis (Section III - The IEP process, 2014).

\section{Low Socioeconomic Status (SES) Student}

Low Socioeconomic Status Students are students who qualify for the National School Lunch Program (United States Department of Agriculture, 2016).

\section{Self-Contained School}

A Self-Contained School is a school or program in public or private day schools designed specifically for children with disabilities. Students receive all of their special education and related services in educational programs at these sites. (FAQs, 2017).

\section{Significance of the Study}


This research study will provide further insight as to what factors may influence post-secondary success for students with ASD. Results from this research can also identify factors that may present barriers to post-secondary success for students with ASD. As a result, educators can identify potential barriers and ensure supports to overcome or avoid these barriers are in place within the design of the community based work experience program. This research will impact my current institution by providing detailed information about the influence of current programs on post-secondary outcomes of our students. Barriers and influences may be identified, inciting changes or improvements to current programming, ensuring the most relevant services are provided to students.

Much of the past literature has focused on students with higher functioning ASD in a public school setting. This study will address the current gap in the research literature regarding predictors of employment outcomes for the general population of students with ASD. Additionally, this research will provide focused information regarding factors that may influence the student population with more severe ASD or those with multiple disability diagnoses, who are educated in a self-contained special education setting.

\section{Summary}

As the number of unemployed youth with disabilities continues to grow, it is essential that educators focus on designing programs that fully prepare students with disabilities to enter the workforce (United States Department of Labor, 2016). As a result, many special education programs have incorporated community based programs to provide real world work experiences to students who may struggle with grasping some of the soft skills involved in employment success (Bellman, et al., 2014; Gragoudas, 2014; 
Lindstrom, et al., 2007; Wehman, et al., 2014). The importance of understanding the connection between CBWE and student post-secondary success is significant, given that WIOA will continue to place an increasing emphasis on full or part time employment for all individuals with disabilities (Marquette, 2016). As these programs become more common within special education, districts should seek to understand the effectiveness of the programs on employment outcomes as well as other factors that may be impacting student success. 
SECTION TWO:

PRACTITIONER SETTING FOR THE STUDY 
Section Two: Practitioner Setting for the Study

\section{Introduction}

Midwest County School District (MCSD) is a unique public school district in that it serves as both a contracted agency providing special education services to 22 other school districts and a specialized public school district. Without MCSD, each district within the county would be charged with creating and providing its own special education program and services. MCSD provides a comprehensive, consistent stream of services to all 22 districts. MCSD also can deliver more specialized services to students whose needs cannot be met in their home school district through MCSD's self-contained schools. Thus, MCSD provides the most individualized, supportive special education services in the Midwest. The focus of this study will be three self-contained secondary special education schools within MCSD.

\section{Background of Organization}

MCSD's mission is to provide technical education and a wide variety of individualized educational and support services designed for each student's successful contribution to the community (Midwest County School District, 2017). MCSD is a unique school district in that it contracts with 22 public school districts to provide special education services to over 23,000 students with disabilities in 265 public schools located in Crown County (District Overview, 2017). Students whose disabilities require more specialized care receive services at one of ten self-contained campuses. Of the ten

campuses, two are grades K-8, two are grades 9-12, two are grades K-12, two are technical school programs, and two are alternative school programs (Midwest County School District, 2017). These schools are staffed entirely by special education teachers, 
administrators, and support staff. Among these ten specialized schools, MCSD serves over 3,500 students with disabilities (Missouri Department of Elementary and Secondary Education, 2017). Students attending these school have disabilities that range from mild to moderate to severe and are cognitive, physical, emotional, or a combination. The population enrolled in all MCSD schools over the last three academic years (2013-2016) has been, on average, 41\% Black, and 53.9\% White, with Asian, Hispanic, Pacific Islander, and Indian making up less than 25\% of the student population (Missouri Department of Elementary and Secondary Education, 2017).

MCSD, like all districts in the state, is evaluated by the Missouri School Improvement Program (MSIP 5, 2014). MSIP 5 is the "state's accountability system for reviewing and accrediting public school districts ("MSIP 5", 2014, p. 2). The Missouri Department of Elementary and Secondary Education (DESE) annually reviews schools throughout the State and computes an Annual Performance Report (APR) score for each school and school district based on five distinct criteria. The five criteria used by MSIP 5 are (a) academic achievement, (b) subgroup achievement (subgroups of students who perform below the state average), (c) college and career readiness, (d) attendance, and (e) graduation ("MSIP" 5, 2014). MCSD has met the MSIP accreditation requirements during the academic years that this study will review (2013-14, 2014-15, and 2015-16) (Missouri Department of Elementary and Secondary Education, 2017).

This study will focus on the college and career readiness piece of the MSIP standards. All secondary schools within MCSD offer a Community Based Vocational Instruction (CBVI) program, also known in this study as a CBWE program. These programs are specifically designed for students with disabilities to participate in their last 
two to four years of high school, typically beginning in 11th or 12th grade. The goal of the CBVI program is to expand job training opportunities beyond the school building to community-based sites where students learn real-world, work appropriate behaviors and skills in a naturally occurring environment (CBVI Guidelines, 2017). Students are continually evaluated and supervised during CBVI by MCSD staff and do not receive wages for their participation in the training program (CBVI Guidelines, 2017). Past research has indicated that participation in work experiences during high school promotes employability of students with disabilities (Bellman, et al., 2014; Gragoudas, 2014;

Holwerda, et al., 2013; Owens, 2011; Wehman, et al., 2014). The CBVI program not only supports MSIP standards, but also aims to assist students in a successful transition from school to work following graduation.

\section{Organizational Analysis}

MCSD’s core values encompass student success, collaboration, integrity, stewardship, continuous improvement, and equity (MCSD, 2017). Part of the continuous learning process within the district includes regular professional development opportunities. Administrators receive monthly specialized professional development trainings. Teachers, specialized staff, and support staff receive professional development related to their specific school building monthly and district-wide professional development quarterly.

MCSD consistently collects data following these trainings and professional development opportunities to ensure that the needs of all MCSD staff are being met. This also allows MCSD to continuously adapt policies and procedures to meet the everchanging needs of their students. In this way, MCSD demonstrates their ability to learn - 
a critical factor associated not only with survival, but also with the continued success of any organization. Research regarding organizational management and development consistently claim that change is the norm and an organization's future largely depends on how well it adapts and learns from its employees and the external environment. Consequently, it is widely regarded that the most critical competency for employees is their ability and willingness to learn (Preskill, 2008 in Gill, 2010). MCSD demonstrates a willingness to continuously adapt and improve as a district to meet the needs of their students.

Additionally, all MCSD's self-contained schools utilize a learning community approach within each building, grouping teachers and support staff who have students with similar goals and abilities together to foster collaborative learning, which allows staff members to feel valued and connected, through a shared vision, purpose, and direction (Gill, 2010). These learning communities meet once per month to review data and share information. MCSD believes that learning communities provide staff the opportunity to share meaningful information from private or public learning and allows for communication to occur for continued growth of MCSD, both within the schools and as a larger learning community (Merriam \& Bierema, 2014). Overall, the learning community approach has been successful, demonstrating that staff feel connected to one another and feel as though they are a valued part of the community (Gill, 2010). This is just one example of the way that MCSD creates a culture of learning and structures that support learning within the district and individual schools (Gill, 2010).

This case study includes three of MCSD's self-contained secondary special education schools: North County, Mid County, and South County high schools. All three 
secondary schools serve students with disabilities whose needs are not able to be met in their home school districts. Each of the three self-contained secondary schools is led by at least two administrators and has between a 1:4 and 1:5 staff to student ratio (Missouri Department of Elementary and Secondary Education, 2017). The Executive Director of Special Schools and Programs directly supervises the principals and vice principals of all three schools. School principals and vice principals meet with the Executive Director monthly and receive monthly administrative training as well. All three secondary schools are Character Education and Positive Behavior Support Intervention (PBIS) braided schools, utilizing a universal approach to behavior, including a common language and expectations for all settings. MCSD incorporates the active teaching of social and behavior skills with the academic curriculum, collects and utilizes data to make individualized student decisions, and provides specialized supports to students with more significant needs (MCSD, 2017).

To fully understand the descriptive statistics of each of the three schools discussed below, it will be important to keep the following information in mind. Under the Individuals with Disabilities Education Act (2004), students with disabilities are eligible to attend school until the age of 21 in the state of Missouri. This means that most of the students attending these three specialized MCSD schools participate in over 5 years of secondary school, thus they are excluded from the 4- or 5-year graduation category for which the Department of Elementary and Secondary Education (DESE) screens. Additionally, the majority of the students in attendance have very high needs disabilities. Postsecondary outcomes for these students include options such as participation in an adult day rehabilitation program, volunteer activities, pre-vocational training, and 
sheltered workshops. However, DESE does not take these options into account when collecting post-secondary outcome information.

\section{North County High School}

North County High School (NCHS) is in a Midwestern state, in the northern part of a large metropolitan county, Crown County, within a low to middle socioeconomic area. Many students who attend NCHS do not live in the immediate area and are transported to the school daily from their homes in the surrounding school districts. The student population has a relatively high free-reduced lunch rate of $78.4 \%$ compared to other schools in the district, which is reflective of the surrounding communities' socioeconomic status (SES) (“School Report Card", 2017). Low SES is an impacting factor on the ability for many families to access supportive services for their students outside of the school community. Regarding post-graduation services, such as preemployment training and sheltered workshops, the geographic area surrounding NCHS is flush with opportunities. However, both transportation and income are often limited, severely restricting families' ability to care for their student, both during school and following graduation.

NCHS employs 114 full-time teachers, specialized service staff, and support staff (MCSD, 2017). NCHS has a student population of 166 students with a student to classroom staff ratio of 1 to 5. The student body is primarily African American (78.1\%) and White (27.1\%), with an attendance rate of approximately 57.6\% ("School Report Card", 2017). MCHS has a 4-year graduation rate of $25 \%$ and a 5 -year graduation rate of 55.56\% ("School Report Card", 2017). Both graduation rates are well below the state graduation rate target of $92 \%$. Interestingly, NCHS was the only one of the three MCSD 
secondary self-contained schools to report students moving on to education programs following graduation. DESE reports that $2.6 \%$ of students from NCHS enrolled in a twoyear college following graduation (“School Report Card”, 2017).

\section{Mid County High School}

Mid County High School (MCHS) is in the central region of Crown County in the same Midwestern state within a middle to high socioeconomic area. Most students who attend MCHS do not live in the immediate geographical area and are transported to the school daily from their homes in the surrounding school districts. The families that live in majority of the districts that MCHS serves are typically in the mid- to high SES range. As a result, students have access to many supportive services offered in the community outside of school. These services can include a variety of therapies, childcare, recreational activities, sports, pre-employment programs, and sheltered workshops.

There are 105 teachers, specialized service staff, and support staff employed at MCHS (MCSD, 2017). MCHS is, in many ways, the polar opposite of NCHS. MCHS has a free-reduced lunch rate of $39.6 \%$ and the attendance rate is $79.6 \%$. MCHS's student body is $61.4 \%$ White, while $31.7 \%$ are identified as African American ("School Report Card”, 2017). MCHS has a student population of 145 students and a student to classroom staff ratio of 1 to 4 . MCHS has a four-year graduation rate of less than $25 \%$ and a five-year graduation rate of 45.45\% ("School Report Card", 2017). MCHS did not report any graduating students moving on to attend a 4-year, 2-year, or technical postsecondary educational program following graduation after the 2016-17 school year (“School Report Card”, 2017).

\section{South County High School}


South County High School (SCHS) is in the southern region of Crown County, in a middle socioeconomic area. Like the other two secondary schools, most students in attendance do not live in the immediate geographical area and are transported to the school daily from their homes in the surrounding school districts. The school districts that feed into SCHS are typically in the middle SES range. Families' ability to support their students through services outside of school varies. Because the SCHS and its surrounding districts are in the southern part of the county, access to post-graduation services such as pre-employment training programs, sheltered workshops, and public transportation are extremely limited.

There are 150 teachers, specialized service staff, and support staff employed at MCHS (MCSD, 2017). SCHS is less diverse than MCHS in that the student population is overwhelmingly White (84.2\%), with a small portion identifying as African American (11.4\%). Like MCHS, SCHS has a free-reduced lunch rate of 34.8\% and an attendance rate of 75.1\% (“'School Report Card”, 2017). SCHS has a student population of 114 students with a student to classroom staff ratio of 1 to 5 ("School Report Card", 2017). SCHS has a four-year graduation rate of $31.25 \%$ and a five-year graduation rate of less than 25\% ("School Report Card", 2017). At the end of the 2016-17 school year, SCHS did not report any graduating students moving on to attend a 4-year, 2-year, or technical postsecondary educational program following graduation ("School Report Card", 2017).

\section{MCSD Leadership Analysis}

MCSD's superintendent has served in this role for the past three years. The superintendent immediately prior passed away unexpectedly in 2014. Although this was a shocking and sad time for the district, the assistant superintendent stepped into the role of 
superintendent, providing continuity and stability. The current superintendent has worked in the district for over 30 years and provides a wealth of knowledge and insight on all aspects of the district.

Because MCSD contracts with 22 districts throughout all of Crown County, collaboration is a vital component in ensuring the success of these partnerships and furthering the success of MCSD (Coryell, 2013). MCSD's policy of collecting feedback from all staff members and promoting an open-door policy at all levels of leadership allows for MCSD to continually gain perspective on their leadership styles as well as the learning taking place within MCSD (Coryell, 2013). MCSD shares this data and the resulting policies and procedures through collaborative processes with others within MCSD to build shared understanding for all employees of the district.

MCSD administrators collaborate with one another through training and professional development opportunities at least once per month, providing opportunities for cross-teaming and learning from each other to ensure success. MCSD creates collaborative experiences that assist in generating personally meaningful, transformative learning by promoting personal reflection in a professional context (Hobbs \& Coiro, 2016).

\section{North County High School Leadership}

Until the 2015-16 school year, NCHS was led by a principal who had been with MCSD for over 30 years. However, after the 2015-16 school year, the principal retired and a new principal was hired from outside the district. The assistant principal remains at NCHS and has held the position for 7 years, with a total of 28 years in the district. 
The recent change in leadership has resulted in staff turnover and instability within the school environment. Leadership has struggled with staff motivation and parent engagement. Some of this disorganization may be attributed to the principal's lack of knowledge of the district procedures and processes as the principal was hired from outside MCSD. The principal has struggled to find secure footing within a school community that, because of the community and the school's specialized nature, is cautious when welcoming outsiders. Additionally, the school is located within a community that experienced extreme social unrest beginning in 2014 and continuing to the present day. The community has experienced riots, excessive crime, and violence that directly affected students and their families. The tension in the community has had a profoundly negative impact on the school community, staff, and students.

Northouse (2016) suggests that leaders must create trust and shared values for people to feel connected and safe. Although the new principal has immersed himself in the school community, he has struggled to build trust with staff. As a result, the collaborative and supportive practices of teachers and staff are strained.

\section{Mid County High School Leadership}

The principal of Mid County High School has served in this role for 11 years and been in the district for 16 years. The assistant principal is relatively new to the school district, having served in the position and the district for two years. The stability of the principal's leadership within the district has fostered strong connections with the community.

Both the principal and assistant principal at MCHS have demonstrated authentic leadership qualities that have resulted in positive influences on teachers and staff. Both 
administrators have shown a continuous commitment to engaging all school community stakeholders and have promoted an open-door policy for staff, parents, and community members. This transparency has created an atmosphere of trust between staff and administration (Owusu-Bempah, Addison, \& Fairweather, 2011; Walumbwa, Avolio,

Gardner, Wernsing, \& Peterson, 2008). The principal's authentic leadership in throughout the school community has created an environment where staff feel comfortable, not only with leadership but with one another. Staff often collaborate outside of their learning communities and feel welcomed in doing so. Additionally, MCHS staff turnover is low and usually attributed to retirement.

\section{South County High School Leadership}

SCHS's principal has served in that role for three years and has been with the district for 11 years. SCHS is a K-12 school and the principal is supported by two assistant principals, one who has served in that role for two years and one who has served in the role for three years. Because all administrators began at SCHS at the about the same time, they have developed a strong partnership.

The administrative team at SCHS functions in a hands-on, student-centered manner. Leadership prides themselves on having detailed knowledge of all students, families, and the communities in which they live. This leadership style allows them to be in tune with the ever-changing needs of the student population. Additionally, it seems they incorporate their knowledge of students to utilize balanced processing when examining the viewpoints of those who disagree with them to understand all perspectives before making a decision (Northouse, 2016). 
Administrators at SCHS demonstrate many characteristics of servant leadership. They are often described as 'student centered', putting the success of the students above all else. Often, the principals will put aside their own administrative tasks to assist teachers in a classroom with a challenging student, eradicating the commonly held belief that principals lead from the comfort of their offices (Shekari \& Nikooparvar, 2011). Administrators have shown that they are capable of handling difficult situations without compromising their focus on student success (Northouse, 2016). By indicating an emphasis on students, administrators at SCHS have fostered a positive organizational climate (Shekari \& Nikooparvar, 2011).

\section{Implications for Research}

All three of the self-contained special education schools described above offer CBWE (also known as CBVI) programs to students who are able to participate. However, DESE only collects information regarding graduates' pursuits of post-secondary education and training programs. The focus of these three secondary schools is often a more practical one - preparing its students to enter the workforce after graduation. Newly implemented governmental policies, such as the Workforce Innovation and Opportunity Act (WIOA) (2004), support the movement towards employment for all persons with disabilities. This study will assist in providing more information about not only the impacts of the CBWE programs on MCSD's student outcomes, but will hopefully encourage DESE to broaden their definitions of post-secondary success as it relates to students with disabilities.

This study has the potential to provide valuable feedback to MCSD regarding the effectiveness of the CBWE program as well as the progress and accomplishment of 
MCSD's organizational goals (Gill, 2010). Each of the three self-contained secondary schools are very diverse in their student population. It is reasonable to assume that student needs will vary, not only within the CBWE programs, but in the student goals and progress following graduation. This study can provide more information as to how best support students in each of these schools as they work towards their post-secondary goals. MCSD prides itself on fostering a culture of learning in an ongoing, systematic manner that is practiced consistently within all the school districts with which it works to succeed as an organization (Mankins \& Steele, 2006). It would seem appropriate that MCSD would value the results and implications of this study to further the structures and programs that support learning within its most specialized educational environments (Gill, 2010).

\section{Summary}

MCSD strives to create a culture of learning while at the same time providing specialized services to meet individual student needs (MCSD, 2017). Although all three of the self-contained secondary schools provide CBWE programs to students, varying geographic locations, communities, and SES impact students' access to resources and, as a result, their post-secondary outcomes. Because the needs of the student populations vary widely, schools will have to adjust programming, thus influencing student outcomes as well. MCSD supports the changing needs of their students by providing school specific and district wide training for all staff and administrators.

Although each leadership style of individual secondary schools differs, they all seem to have the same goal at heart - student success. All three schools are at differing levels of leadership, ranging from adjusting to a new leader to continuing the current 
leadership traditions. Overall, leadership within each school seems to be based on the needs of student population, furthering MCSD's dedication to support services designed for each individual student (MCSD, 2017).

Differing leadership styles and administrator longevity may affect student success and their abilities to meet post-secondary goals. Because all three schools have different leadership teams, the way the CBWE programs are implemented may differ at each school. The organization and leadership of the district and at the individual school level has the potential to impact the post-secondary outcomes of students. 
SECTION THREE:

SCHOLARLY REVIEW FOR THE STUDY 


\section{Section Three: Scholarly Review for the Study}

\section{Introduction}

In May of 2016, the local Midwest newspaper headline reads: "School once meant isolation. Now, autistic student is 'The Mayor' of Parkway West High” (Crouch, 2016). The headline sounds promising, conveying a school atmosphere most students with disabilities dream of - one that is more than inclusive, embracing students with disabilities and celebrating their specific skill sets. Now, fast forward to April 2017. Nearly one year later, the headline now reads: "Autism makes life after high school a struggle for the 'Mayor of Parkway West' (Taketa, 2017). The message is clear - the world of work is unforgiving for youth with Autism Spectrum Disorders (ASD) and other disabilities. While public schools have made an effort to become inclusive, they still lack programming to adequately prepare students with disabilities for life outside of the school community.

The transition years immediately following graduation are the most difficult for those with disabilities. During that time, those with ASD are at the greatest risk for disengagement from vocational or educational activities (Taylor, Smith, \& Mailick, 2014). In fact, over half of youth with ASD are not participating in education or paid employment activities during first two years after graduation from high school (Shattuck, Narendorf, Cooper, Sterzing, Wagner, \& Taylor, 2012). However, the American government continues to push for employment of youth with disabilities (Fabian, et al., 2016). One of the most well-known policy initiatives is the Workforce Innovation and Opportunity Act (WIOA), a bill passed in 2014, whose implementation placed further stipulations on enhancing services and supports for youth with disabilities as they enter 
the workforce (Education and Workforce Committee of the United States House of Representatives, 2014; Marquette, 2016; The Arc, 2015). While many media outlets have focused on the recent efforts of corporations to recruit and hire adults with disabilities to comply with WIOA, finding and maintaining employment continues to be a struggle for those with disabilities (Erbentraut, 2015; Roux, et al., 2013).

Current data further supports a disconnect between high school and the world of work for students with disabilities. Unemployment rates for youth with disabilities are $36.8 \%$ for those between the ages of 16 and 19 , and over $17 \%$ for those between the ages of 20 and 24 (United States Department of Labor, 2016). Numbers cannot tell the story of all the extraneous factors that impact the success of youth with disabilities in the world of work. For one, these statistics do not describe the type and severity of the disability(s) of those youths struggling to find their place in the world after high school. Those with more severe or varied disabilities, such as those with ASD or more severe developmental disabilities, often experience impairments in social and communicative skill functioning that can limit their ability to work, which in turn, leads to an underutilization of their skills (Holwerda, van der Klink, de Boer, Groothoff, \& Brower, 2013). The supports needed to ensure post-secondary employment outcomes of individuals with severe and multiple disabilities can differ vastly. While the first headline seems to indicate that the school community can foster a supportive network for success for those with more severe disabilities, such as ASD, the second headline implies a harsher reality. Students with disabilities need to develop skills to become employable before they graduate if they wish to survive in the world beyond high school. 
Past literature has touched on some of the more obvious factors that impact employment for youth with disabilities, such as lack of employment training, family and community supports, socioeconomic status, and self-advocacy. (Bellman, et al., 2014; Gragoudas, 2014; Lindstrom, et al., 2007; Saunders, et al., 2015; Trainor, et al., 2015; Wehman, et al., 2014). Although research has indicated that those with ASD and other disabilities have difficulty maintaining employment, the more specific influential factors that determine long-term employment for these individuals has not been fully explored (Holwerda, et al., 2013; Shattuck, et al., 2012). Additionally, much of the research contains information regarding training and supports for students with disabilities within a typical general education environment. However, many students with multiple or more severe disabilities, such as those with ASD, participate in public education within a selfcontained environment to ensure their needs are adequately met. Participating in these self-contained schools or programs limits those students' experiences with real-life work environments, one of the factors frequently cited as necessary for post-secondary employment success (Bellman, et al., 2014; Gragoudas, 2014; Holwerda, et al., 2013; Owens, 2011; Wehman, et al., 2014). Past research does not discuss the transition needs of youth in those self-contained educational settings as they prepare to graduate and enter the workforce. The present study will provide insight into the aspects of support that are most beneficial for those students with more significant or severe disabilities, such as ASD, who are participating in a self-contained special education setting.

In the following subsections, several key aspects of past literature regarding transition for students with disabilities will be discussed to highlight the current needs in supportive services and educational programming to ensure successful post-secondary 
outcomes for students with more intensive disabilities. The aspects discussed below are critical for post-secondary transition success for all youth with disabilities. Although the population of students with multiple and more severe disabilities, such as ASD, continues to be overlooked in the literature, this study aims to bring focus to the need for research regarding transition preparation for students with high need disabilities. This study will discuss some of the key facets of these students that must be considered when preparing for life after high school.

\section{Review of Current Scholarship}

\section{High School Work Experiences}

Some studies cite academic preparation and involvement as an indicator of postsecondary success for students with disabilities (Lehmann, Bassett, Sands, Spencer, \& Gliner, 1999; Newman, et al., 2016). The reasoning behind this concept is that the more rigorous the students' academic coursework during their high school years, the more likely those students with disabilities will be more likely to a) pursue education beyond the high school level and b) disclose their disability and seek out supports (Lehmann, et al., 1999; Newman, et al., 2016). Other studies focus on the use of real-world activities to continue academic education while at the same time developing vocational skills that are easily transferable to the post-secondary world of work (Holwerda, et al., 2013). A large body of research indicates that participation in work experiences during high school promotes employability of students with disabilities (Bellman, et al., 2014; Gragoudas, 2014; Holwerda, et al., 2013; Owens, 2011; Wehman, et al., 2014). More specifically, those students with ASD who engage in stimulating vocational activities over time show positive changes in behavioral development and daily living abilities throughout 
adulthood (Smith, Maenner, \& Seltzer, 2012; Taylor, et al., 2014). Thus, vocational activities and experiences in high school appear to promote the success of youth with disabilities in their post-secondary employment goals, no matter the severity of their disability.

For youth with ASD, positive behavioral changes and skill acquisition are likely influenced by the surrounding environment and the experiences taking place within that environment (Taylor, et al., 2014). Work-based learning programs increase communication, problem-solving and self-confidence of students with disabilities while also promoting motivation, job-related skills, relationship building, and self-advocacy (Bellman, et al., 2014; Wehman, et al., 2014). Participation in employment training in the classroom is also a contributing factor to an increased likelihood that youth with disabilities will be successful in obtaining employment after graduation (Gragoudas, 2014; Owens, 2011; Wehman, et al., 2014). For students with ASD, participating in vocational activities increases functional independence and decrease maladaptive behaviors, allowing students to participate more fully in their communities (Smith, et al., 2012; Taylor \& Seltzer, 2011; Taylor, et al., 2014). Therefore, special education programs can deliver the greatest benefit to their students with disabilities by incorporating work skills training programs in the classroom and school community. Research continues to show that these programs improve the employability of students with disabilities by providing positive exposure to work environments (Holwerda, et al., 2013; Wehman, et al., 2014).

While it seems apparent that high school work experiences may benefit students with disabilities as they transition to life after high school, many unanswered questions 
remain. Current research neglects to address the growing population of students with disabilities who participate in public education in a nontraditional school setting, such as a self-contained school program or building. What is the post-secondary outlook for students with ASD or multiple disabilities, who possess valuable job skills, but may be limited by their communication abilities? Although there is a growing population of students with intensive post-secondary needs due to more severe disabilities, the research has largely ignored this population. These students certainly possess the ability to contribute to the workforce in many ways, but the supports needed to connect this population with best-fit employment opportunities are relatively unknown. The disparity for those with more severe disabilities between high school success and employment success is clear. More research is needed on how to best provide these interactive work experiences to students with more intensive disabilities to bridge the gap and ensure a smooth transition to life after high school.

\section{Networks of Support}

Another key component of post-secondary success for students with disabilities is family support and community collaboration. Many students with ASD and other disabilities show a dramatic decrease in functional independence as well as an increase in maladaptive behaviors following their exit from high school, placing these students at a high risk for disengagement from the outside world (Smith, et al., 2012; Taylor \& Seltzer, 2011). Often, it is parents and community agencies who serve as the liaisons between students and employers. Research has indicated that family supports and community involvement are strong predictors of positive employment outcomes of students with disabilities (Fabian, et al., 2016; Holwerda, et al., 2013; Lindstrom, et al., 2007; Miller- 
Warren, 2016; Trainor, et al., 2015; Wehman, et al., 2014). These support networks and community relationships are paramount in ensuring that students with disabilities are successful in meeting their post-secondary goals.

Parent expectations and supports are key in not only facilitating the transition process, but in ensuring that youth with disabilities succeed after graduation (Lindstrom, et al., 2007; Wehman, et al., 2014). Family members can influence the employment outcomes of individuals with disabilities simply by modeling and sharing information regarding their own work experiences (Eisenman, 2007; Holwerda, et al., 2013). It is the school community that provides the largest impact on post-secondary employment outcomes. Schools often provide direct assistance in forming partnerships between parents and outside agencies, serving as a liaison to ensure continuity of services after students graduate. Strong cooperative relationships are indicative of positive outcomes for students with disabilities (Miller-Warren, 2016; Trainor, et al., 2015). Research has shown a need for schools to promote a more collaborative environment where all stakeholders feel comfortable asking for assistance in the transition process (Fabian, et al., 2016; Miller-Warren, 2016).

Additionally, the role of the community is vital to the success of students with disabilities as well. For youth with ASD, research has indicated that functional independence often decreases while maladaptive behaviors increase in the years immediately following high school graduation (Smith, et al., 2012; Taylor \& Seltzer, 2010). To prevent this regression in skills and promote continued independence, youth with ASD and other disabilities need strong, supportive vocational experiences that ease the transition from school to the world of work. Community agencies can offer a wide 
range of resources that can enable student success after high school (Hoover, 2016). One underutilized technique that connects students with community agencies while they are still in high school called community mapping, allows parents, teachers, and students to gain as much information as possible about the assets and services located within their community (Hoover, 2016). Community mapping can assist in fostering relationships between students and the agencies they will be interacting with once they graduate as well as creating a collaborative environment with community employers. Research on community mapping as a tool to further the success of students with disabilities is limited, although the concept appears promising (Hoover, 2016).

The support of parents along with the collaboration of community agencies can create successful post-secondary outcomes for students with disabilities. However, more research is needed regarding how these networks of support can be utilized for those students with more severe disabilities. Research is also needed as to why these supportive relationships may be underutilized for a population whose success appears to depend entirely on these supporting networks.

\section{Multiple Disability Diagnoses}

Data suggests that, over the last decade, the prevalence of ASD diagnoses has increased by $11 \%$ or 1 in 88 children (Center for Disease Control, 2016; Holwerda, et al., 2013; Manning-Courtney, Murray, Currans, Johnson, Bing, Kroeger-Geoppinger, Sorenson, Bass, Reinhold, Johnson, \& Messerschmidt, 2013; Tchaconas \& Adesman, 2013). Specifically, those diagnosed with ASD are more likely to also experience cooccurring disorders, such as genetic syndromes or psychiatric disorders (Saunders, et al., 2015; Taylor, et al., 2014). For example, a significant portion of those diagnosed with 
ASD also have a diagnosis of Intellectual Disability (ID; Peacock, Amendah, Ouyang, \& Gross, 2012; Saunders, et al., 2015; U.S. Department of Health and Human Services, Health Resources and Services Administration, Maternal and Child Health Bureau, 2013). Multiple disability diagnoses often increase the support needs of these students in both the school and community environments. Past literature has demonstrated that individuals diagnosed with ASD along with a second disability, such as ID, are less likely to be employed than those with a singular diagnosis of ASD (Taylor \& Seltzer, 2011).

While much of the past research on those diagnosed with ASD and multiple disabilities focuses on a much younger age range, scholars and practitioners have begun to recognize that ASD is a lifelong disability with impairments that can significantly impact quality of life throughout adulthood (Taylor, et al., 2014). Research on young adults with ASD is limited and relatively little is known about factors that may help to promote positive adult development for those with ASD (Taylor, et al., 2014). Although some literature suggests that the symptoms of ASD decrease as age increases, research is still sparse regarding the impact of symptoms for older persons with ASD (Church \& Coplan, 1995; Schopler, Van Bourgondien, Wellman, \& Love, 2010; Taylor, et al., 2014). Additionally, research is limited as to how ASD and multiple disabilities impact those older youth as they transition from high school to the world of work. More information is needed regarding how youth with ASD and a secondary disability interact with the world of work following graduation from high school.

\section{Socioeconomic Impact}

Often, students with ASD or multiple disabilities require more intensive educational supports, including additional supportive services outside the school 
environment such as behavioral therapy, physical therapy, speech therapy, and childcare. For caregivers, the monetary and time costs of these services add up quickly. Some literature suggests that the cost of caring for a person with ASD during his/her lifetime has been estimated to be $\$ 1.4$ million in the United States (Buescher, et al., 2014).

Many families of children with ASD and other disabilities rely on state and federally funded services, such as Medicaid waiver services and Supplemental Security Income (SSI), but not all supportive services are covered through these programs (Saunders, et al., 2015). Some services may even require partial or complete funding from individuals, families, or caregivers, creating an additional monetary burden for those households already experiencing financial stress (Mayes \& Calhoun, 2011).

For those diagnosed with ASD or multiple disabilities, the cost of continued care has the potential to increase dramatically after graduation from high school. The intensive needs of this population impact caregivers' ability to maintain employment, which in turn negatively affects the financial resources of the household (Cidav, Marcus, \& Mandell, 2012). Many caregivers of persons with ASD frequently report financial difficulties and, for those with multiple diagnoses, the economic strain can be compounded (Saunders, et al., 2015).

Limited means can impact employability, not only for those with disabilities, but also for their caregivers. Cidav, et al. (2012) reported that mothers of children with ASD were less likely to be employed and, if they were employed, worked fewer hours per week or earned significantly less than mothers of children with other health limitations. For those children with ASD, lower socioeconomic status has limited participation in stimulating occupational activities after high school, as families have increased financial 
barriers regarding access to supportive services (Liptak, Benzoni, Mruzek, Nolan, Thingvoll, Wade, \& Fryer, 2008; Thomas, Ellis, McLaurin, Daniels, \& Morrissey, 2007). Further, financial stress within the household may exacerbate the symptoms of ASD and other disabilities, interfering with parent or caregivers' abilities to implement techniques and supports with their child as well as the person with ASD's ability to function independently in the community (Mayes \& Calhoun, 2011). These lower SES households may also lack the resources to implement stress-relieving activities, such as child care, entertainment, or family vacations, resulting in decreasing coping skills for caregivers (Mayes \& Calhoun, 2011). Increased household stress, in turn, creates elevated symptoms of those children with ASD, creating a detrimental cycle within the household, impacting not only caregivers, but individuals with disabilities' opportunities for success as well.

Past research has made it clear that those students with ASD and multiple disabilities require more intensive supports as they transition to life after high school (Mayes \& Calhoun, 2011; Saunders, et al., 2015). The cost of these programs and supports is high, placing them out of reach for many families or caregivers who are struggling financially (Liptak, et al., 2008; Mayes \& Calhoun, 2011; Thomas, et al., 2007). Research has not addressed the long-term impact of limited financial household resources on students with ASD or multiple disabilities as they navigate the increasingly complicated world of work after high school. This broad scale issue is one that needs to be further explored so that programs and supportive services can adequately address the holistic needs of those with ASD or multiple disabilities and their families.

\section{Summary}


There are many facets to employment success for those with high needs and multiple disabilities. Past research has clearly indicated that work-based experiences, strong support networks, socioeconomic status, and multiple disability diagnoses all play key roles in influencing the employment outcomes of those with disabilities. Although research regarding ASD and its impacts later in adulthood is growing, there is still a deficit in information regarding the portion of the population with more significant disabilities. While there is a place in the world of work for these individuals and their skills, more information is needed to determine how best to assist those with ASD in not only meeting their post-secondary employment goals, but maintaining those goals over time.

This study is relevant not only to those individuals with ASD and other high needs disabilities who desire to be part of the workforce, but to current special education teachers, school counselors, transition facilitators, district administrators, parents, and community agencies as well. Students with ASD and multiple disabilities can bring valuable skills and perspectives to the workplace. The goal of special education teachers, along with school counselors and other transition support staff, is to not only teach students employment skills, but also instill in students the ability to advocate for themselves to ensure long-term success in the world of work. District administrators are invested in student outcomes, as they are vital for funding, accreditation, and more. Although schools provide an intensely supportive community, parents must learn what to expect when navigating a new world for their student without the assistance of the school after graduation. Community agencies and businesses will benefit in gaining further knowledge regarding supports for potential employees, resulting in an increased ability to 
provide appropriate accommodations to these individuals. This enables employers to tap into the valuable skill sets of these individuals while acquiring qualified employees. Special education teachers, school support staff, and administrators must build programs that focus on meeting the more intensive needs of students with disabilities to ensure the success in the world of work for these students after graduation.

The gap between high school and the world of employment is a tenuous one for individuals with more intensive or multiple disabilities. This study will help inform key community partners and assist in cooperative approaches to successful transition and employment outcomes for those students with more intensive disabilities. By providing an in-depth look at the many factors that influence employability for those students with more intensive disabilities, like ASD or multiple disabilities, community partners can collaborate to create more effective programs and practices to promote the success of this growing population. 
SECTION FOUR:

A WHITE PAPER REPORT 
Section Four: A White Paper Report

\section{Table of Contents}

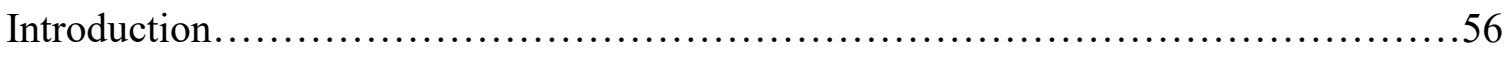

Research Process.........................................................56

Factors Impacting Postsecondary Success...................................57

Research Findings......................................................61

Limitations and Recommendations......................................... 62

Implications for Practice................................................64

References.............................................................66 


\section{Introduction}

The purpose of this research study was to explore factors that could potentially impact postsecondary outcomes for students with Autism Spectrum Disorder (ASD) in the self-contained special education school setting. This report contains a brief overview of current research relating to factors that may influence postsecondary success for students with ASD. The report also includes a brief description of the research process used to investigate three specific predicting factors of graduates of three self-contained secondary schools within Special School District between the academic years of 2013-14 and 2016-17. Findings, limitations, implications for future Community-based Vocational Instruction (CBVI) programming, and future policy creation as a result of this study are discussed as well.

\section{Research Process}

Archival data was collected following approval of this research project by MCSD's Evaluation and Research Department. Only students who graduated from MCSD's three self-contained high schools, NCHS, SCHS, and MCHS, between the academic years of 2013-14 and 2016-17, with an educational diagnosis of ASD were included in the study. Additional information gathered included students' postsecondary outcomes six months post-graduation, students' qualification for free and reduced lunch, participation in CBVI programs, and the presence of additional disability diagnoses.

There were a total of 70 graduates who met the criteria for this study. Of these 70 graduates, 35 met their postsecondary goals, 32 qualified as low socioeconomic status, as determined by their qualification for free and reduced lunch program, 23 had a co- 
occurring disability, and 45 participated in a CBVI program during high school. A breakdown of these factors by graduation year can be seen in Figure 1 below.

Figure 1. Descriptors of Graduates with ASD by Year

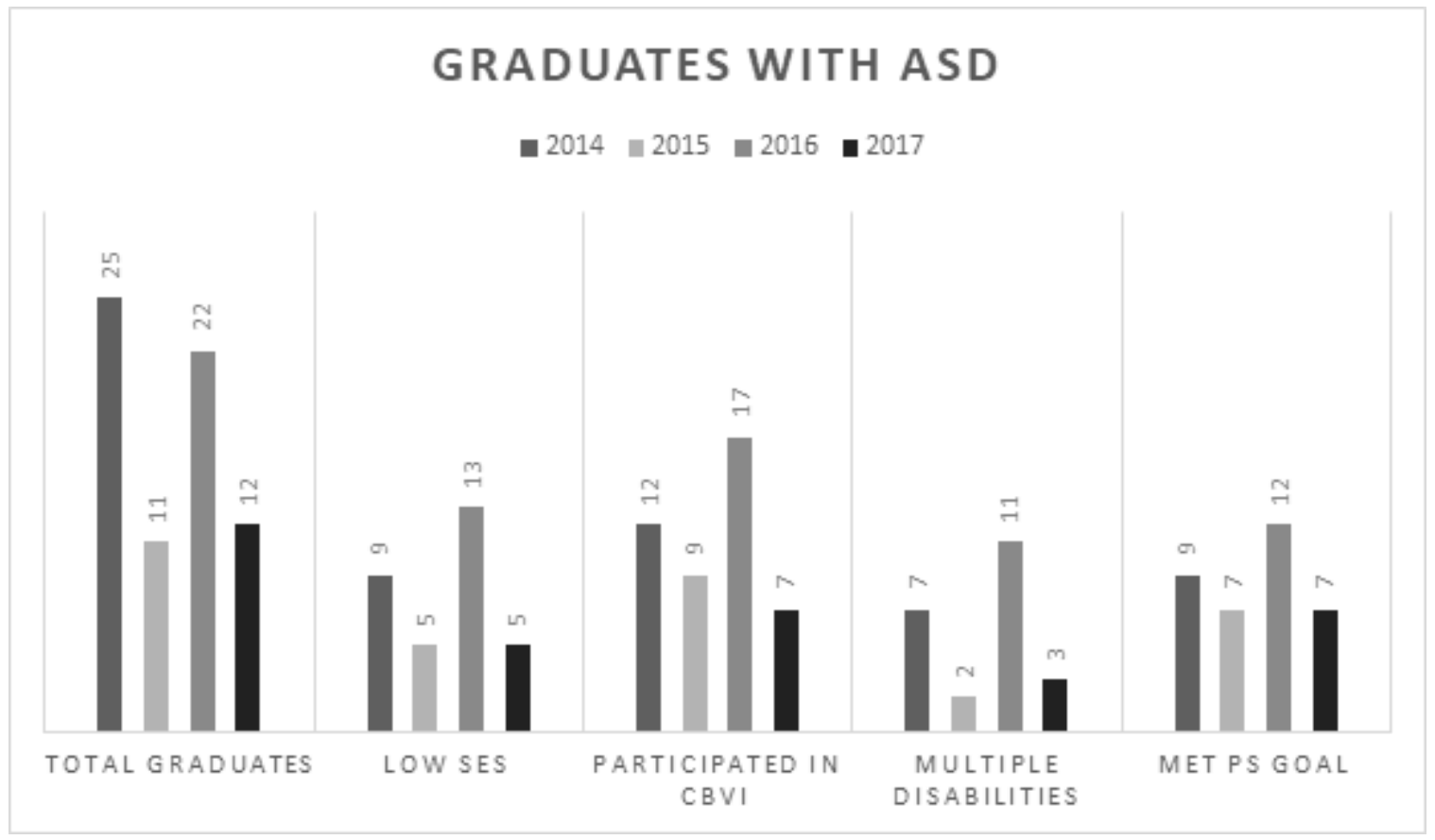

\section{Data Analysis}

Pearson's Chi Square test was utilized to determine the potential effect of each variable on postsecondary outcomes. Chi Square provides versatility in summarizing the relationship between two discrete, categorical variables (Field, 2013). A log-linear analysis was calculated, determining the relationship between the three predictors for this study (Tabachnick \& Fidell, 2007).

\section{Factors Impacting Postsecondary Success}

\section{Socioeconomic Status}

Research has long cited family support as a precursor of postsecondary success for students with ASD (Benz, Yovanoff, \& Doren, 1996; Bellman, Burgstahler, \& Ladner, 2014; Gragoudas, 2014; Trainor, Morningstar, \& Murray, 2015; Wehman, Sima, 
Ketchum, West, Chan, \& Leucking, 2014). The likelihood of families with children with ASD experiencing financial strain is great (Buescher, Cidav, Knapp, \& Mandell, 2014; Saunders, Tilford, Fussell, Schulz, Casey, \& Kuo, 2015). Yet, current research reports that, for youth with disabilities to be successful in finding and maintaining employment, additional outside supports are necessary, specifically financial supports (Holwerda, van der Klink, de Boer, Groothoff, \& Brouwer, 2013; Saunders, et al. 2015).

For caregivers, the monetary and time costs of additional supportive services, such as behavioral therapy, physical therapy, speech therapy, and childcare, add up quickly. Some literature suggests that the cost of caring for a person with ASD during his/her lifetime is an estimated \$1.4 million in the United States (Buescher, et al., 2014). As a result, many families of children with ASD and other disabilities rely on state and federally funded services, such as Medicaid waiver services and Supplemental Security Income (SSI). Unfortunately, not all supportive services are covered through these programs, and many services require partial or complete funding from individuals, families, or caregivers (Saunders, et al., 2015). This creates an additional monetary burden for those households already experiencing financial stress (Mayes \& Calhoun, 2011).

Due to these added expenses, families often incur financial hardships, such as job loss, and limited employability, making accessing outside supportive services difficult (Cidav, Marcus, \& Mandell, 2012; Liptak, Benzoni, Mruzek, Nolan, Thingvoll, Wade, \& Fryer, 2008; Saunders, et al., 2015; Thomas, Ellis, McLaurin, Daniels, \& Morrissey, 2007). Lack of financial supports often causes added stress to families, which, in turn, creates elevated symptoms of those children with ASD, creating a detrimental cycle 
within the household, impacting not only caregivers, but individuals with disabilities' opportunities for success as well. (Mayes \& Calhoun, 2011). Households experiencing financial stress may also lack the resources to implement stress-relieving activities, such as child care, entertainment, or family vacations, resulting in decreased coping skills for caregivers (Mayes \& Calhoun, 2011).

Students with ASD and multiple disabilities require more intensive supports as they transition to life after high school and the assistance provided by the school fades (Mayes \& Calhoun, 2011; Saunders, et al., 2015). The cost of these programs and supports is high, placing them out of reach for many financially strapped families or caregivers (Liptak, et al., 2008; Mayes \& Calhoun, 2011; Thomas, et al., 2007). Research has not addressed the long-term impact of limited financial household resources on students with ASD as they navigate the increasingly complicated world after high school. Financial strain experienced by families and caregivers of students with ASD and other disabilities is a broad scale issue that needs to be further explored so that programs and supportive services, both during and after high school, can adequately address the needs of those with ASD or multiple disabilities and their families. This report will explore the potential influence of low SES, defined as students who qualify for the National School Lunch Program, on the postsecondary outcomes of students with ASD (United States Department of Agriculture, 2016).

\section{Multiple Disabilities}

As research regarding ASD continues, it finds that a significant portion of the population of those diagnosed with ASD are also diagnosed with a second disability, such as genetic syndromes or psychiatric disorders (Saunders, et al., 2015; Taylor, Smith, \& 
Mailick, 2014). For example, a significant portion of those diagnosed with ASD also have a diagnosis of Intellectual Disability (ID; Peacock, Amendah, Ouyang, \& Gross, 2012; Saunders, et al., 2015; U.S. Department of Health and Human Services, Health Resources and Services Administration, Maternal and Child Health Bureau, 2013). A second disability diagnosis can result in compounded difficulties for students already facing significant challenges, both in the school and home environments, as well as the transition into the community post-graduation (Saunders, et al., 2015). Research indicates that individuals with co-occurring disabilities are less likely to be employed than those with a singular diagnosis of ASD (Taylor \& Seltzer, 2011). With the increasing push from the American government for employment for all, those with ASD and a cooccurring disability will encounter added hardships.

As it stands, research is limited on the ability of those with co-occurring disabilities to reach postsecondary goals, as well as what specific supports are needed to ensure this success following graduation. This report aims to shed light on the potential impact of co-occurring disabilities on postsecondary success. Additionally, this report will discuss how MCSD can address the postsecondary needs of this population through current programming and future policy creation.

\section{Community-Based Vocational Instruction Programs}

As knowledge continues to grow regarding ASD and other disabilities, a shift in the research focus is emerging. Recent studies focus on real-world activities to continue education while at the same time developing work skills that are easily transferable to the post-secondary world, indicating a shift in thinking that participation in work experiences during high school promotes employability of students with disabilities (Bellman, et al., 
2014; Gragoudas, 2014; Owens, 2011; Wehman, et al., 2014). Focusing on employment skills flips the conversation away from the previous academic focus of special education programming related to post-secondary success.

Legislation regarding transition for students with disabilities has always focused on outcomes, yet recently it has begun to emphasize the need for the development of employment skills along with community experiences to aid in a smooth transition from school to post school activities (Kohler, 1996; IDEA, 2004). In fact, The Individuals with Disabilities Education Act's (IDEA) (2004) transition standards closely align with the goals of many community-based work experience (CBWE) programs provided in special education schools. CBWE programs, also referred to as Community Based Vocational Instruction (CBVI) programs, represent experiences that may include in-school or after school opportunities, or experiences outside the traditional school setting (including internships), that are provided in an integrated environment to the maximum extent possible (Education and Workforce Committee of the United States House of Representatives, 2014).

Participation in structured employment training in the classroom and/or school community is one demonstrated factor that appears to increase the likelihood that youth with disabilities will be successful in meeting goals after graduation (Gragoudas, 2014; Kohler, 1996; Owens, 2011; Wehman, et al., 2014). Additionally, CBVI programs have been shown to increase skills areas that students with ASD typically lack, such as communication, problem solving, and self-confidence while also promoting motivation, job-related skills, relationship building, and self-advocacy (Bellman, et al., 2014; Kohler, 
1996; Wehman, et al., 2014). This report will consider the potential impact participation in CBVI programs may have on postsecondary success for students with ASD.

\section{Research Findings}

This study was designed to determine predictors that impact postsecondary outcomes for students with ASD. Differences were explored in terms of socioeconomic status, multiple disability diagnoses, and participation in CBVI via Pearson's chi square analysis and a log-linear analysis. Though past research has theorized an impact of each of the three predictor variables on postsecondary outcomes, results of this study indicated that no significant relationship exists between any of the three variables explored and post-secondary outcomes of students with ASD.

\section{Limitations and Recommendations}

One limitation of this study was sample size. At the time of this study, the district had only recently begun to collect post-secondary outcome data electronically. Obtaining a sufficient sample size of at least 30 students, data included four academic years, 20142017. Data collected included graduates of all three self-contained special education secondary school sites to ensure the largest sample size possible. Despite this, the sample size yielded only 70 who fit the criteria outlined by this study. MCSD should consider examining longitudinal data to support consistency among cohorts and will allow researchers to pinpoint influencing variables with more precision.

A second limitation is students' qualification for free and reduced lunch. The determination of eligibility for the free and reduced lunch program comes from the student's home district, not MCSD. Some districts, due to the SES of the community they serve, automatically qualify all students for free and reduced lunch upon enrollment. 
Therefore, qualification for free and reduced lunch may not provide an accurate depiction of student SES.

Past research has indicated that, due to intensive support needs, many families of children with ASD experience financial strain and limited access to supportive services needed to ensure postsecondary success (Cidav, et al., 2012; Mayes \& Calhoun, 2011; Saunders, et al., 2015). However, results of this report indicate that low SES may not have a significant impact on postsecondary outcomes for students with ASD. As previously mentioned, many families receive direct support services throughout their child's lifetime through publicly funded programs, such as Medicaid waiver services and SSI. These programs are needs based, so families with lower incomes may qualify for more supports. Past research has also argued that using free and reduced lunch qualification is not always an accurate representation of household SES (Harwell \& LeBeau, 2010). To gain a more accurate perspective of the way in which SES impacts families of students with ASD, MCSD should consider other factors such as household income, number of dependents in the household, and/or other family stressors (Harwell \& LeBeau, 2010).

A third factor that may have impacted the outcome of the analysis was the use of discrete data. ASD has long been categorized as a spectrum disorder, meaning that the range of the impact of the disability on level of functioning varies by individual (Ozonoff, South, \& Miller, 2000). The definition of ASD has continually evolved over the past 50 years and will likely continue to do so as more is learned about the disability (Hassall, 2017). Furthermore, there is no clear determination regarding the degree to which ASD, or any disability, will affect an individual's level of functioning (Ozonoff, et 
al., 2000). There is no doubt that those with ASD and other disabilities will encounter obstacles as they transition from school to the adult world. But, by categorizing participants in a simple yes/no fashion, full impact of the disability may not have been realized within this analysis. For example, the dichotomous categorization does not consider other possible influencing factors, such as IQ, academic proficiency, or goal achievement prior to graduation, to name a few. MCSD should consider these factors in the future as it examines the postsecondary success of the population with ASD in selfcontained schools.

MCSD must also consider the measures by which postsecondary outcome data is collected. The Graduate Six Month Follow up is a district-created tool, potentially limiting its reliability and validity. Graduate data is collected by many different employees of MCSD, allowing for some subjectivity in the interpretation of whether or not postsecondary goals have been met. For instance, there is a potential for affinity bias to occur in the recording of the data if the collector has a relationship with the graduate's family. MCSD should consider fully exploring the reliability and validity of the tool used to gather data as well as ways to preserve objectivity during data collection.

The time frame at which data is collected should also be considered. MCSD is unique in the way it provides comprehensive services to the special education population. However, community resources that are accessible to graduates after high school are not always parallel in the quality or quantity of their services. Often, programs are full or funding is limited, placing graduates on wait lists for programs and services after graduation. MCSD should consider longitudinal data at the one- or two-year mark, to fully gauge if students have accomplished their postsecondary outcomes. For example, 
students who were previously on waiting lists for programs during the Graduate Six Month Follow Up data collection period may be participating in programs at the one- or two-year mark, effectively meeting their postsecondary goals. MCSD should consider exploring the data collected at longer time intervals to obtain a better assessment of the potential impact of variables explored in this study.

\section{Implications for Practice}

This report serves as a resource for MCSD administrators, school practitioners, and policymakers, as well as community agencies considering how to best support students with ASD as they transition into the community following graduation. Although data analysis did not reveal a statistically significant impact, past theory has indicated that each of the factors considered has the potential to impact individual students with ASD. As MCSD's practices and policies continue to evolve to meet the evolving needs of its students, it will be important to consider each of these variables and their potential impact on postsecondary student success.

As MCSD evaluates its current practices, it cannot discount past research regarding the effectiveness of CBVI programs on postsecondary transitions (Bellman, et al., 2014; Gragoudas, 2014; Kohler, 1996; Lindstrom, Paskey, Dickinson, Doren, Zane, \& Johnson, 2007; Owens, 2011; Wehman, et al., 2014). However, this research should be interpreted and utilized carefully. Because the degree of severity of which ASD impacts the student's functioning can vary, a flexible CBVI program that is designed to meet individual needs must be created. Data indicated that only $64.3 \%$ of graduates with ASD participated in a CBVI program. If MCSD's goal is postsecondary success for all, CBVI programs need to be designed to include all students at all levels of functioning. Because 
some of MCSD's CBVI programs exist in self-contained environments, administrators and practitioners are provided a unique opportunity to create and implement a more intensive community integration program, further paving the way for a smooth transition into adulthood for students with ASD. This report serves as a starting point for MCSD's administrators, practitioners, policy-makers, and other key stakeholders, to question the importance of key factors emphasized in past research to positively impact the futures of students with ASD. With these aspects in mind, MCSD's administrators and practitioners must evaluate current CBVI programs with a critical eye to ensure the needs of all students with ASD are met, both in the self-contained schools and as students transition into their next phase of life. 


\section{References}

Bellman, S., Burgstahler, S., \& Ladner, R. (2014). Work-based learning experiences help students with disabilities transition to careers: A case study of university of Washington projects. Work, 48, 399-405. https://doi.org/10.3233/WOR-131780

Benz, M.R., Yovanoff, P, \& Doren, B. (1997). School-to-work components that predict postschool success for students with and without disabilities. Exceptional Children, 63(2), 151-165.

Buescher, A.V., Cidav, Z., Knapp, M., \& Mandell, D.S. (2014). Costs of autism spectrum disorders in the United Kingdom and the United States. Journal of the American Medical Association Pediatrics, 168, 721-728.

http://dx.doi.org/10.1001/jamapediatrics.2014.210

Cidav, Z, Marcus, S.C., \& Mandell, D.S. (2012). Implications of childhood autism for parental employment and earnings. Pediatrics, 129, 617-623.

http://dx.doi.org/10.1542/peds.2011-2700

Education and Workforce Committee of the United States House of Representatives (2014). Congress passes WIOA: Overhaul of America's job training programs headed to president's desk following strong bipartisan support from Congress. Retrieved from: http://mawd.us/congress-passes-wioa/

Field, A. (2013). Discovering statistics using IBM SPSS statistics $\left(4^{\text {th }}\right.$ Ed.). Thousand Oaks, CA: Sage.

Gragoudas, S. (2014). Preparing students with disabilities to transition from school to work through self-determination training. Work, 48(3), 407-411. https://doi.org/10.3233/WOR-131782 
Harwell, M. \& LeBeau, B. (2010). Student eligibility for free and reduced lunch as an SES measure in education research. Educational Researcher, 39(2), 120-131.

Holwerda, A., van der Klink, J.J.L., de Boer, M.R., Groothoff, J.W., \& Brouwer, S. (2013). Predictors of sustainable work participation of young adults with developmental disorders. Research in Developmental Disabilities, 34, 2753-2763.

Individuals with Disabilities Education Act. (2004). Transition services. Retrieved from: https://sites.ed.gov/idea/regs/b/a/300.43

Kohler, P.D. (1996). A taxonomy for transition programming: linking research and practice. Washington, DC: U.S. Department of Education, Office of Educational Research and Improvement.

Lindstrom, L., Paskey, J., Dickinson, J., Doren, B., Zane, C., \& Johnson, P. (2007). Voices from the field: Recommended transition strategies for students and staff. Journal for Vocational Special Needs Education, 29(2), 4-15.

Liptak, G.S., Benzoni, L.B., Mruzek, D.W., Nolan, K.W., Thingvoll, M.A., Wade, C.M., Fryer, G.E. (2008). Disparities in diagnosis and access to health services for children with autism: Data from the National Survey of Children's Health. Journal of Developmental and Behavioral Pediatrics, 29, 152-160.

Mayes, S.D. \& Calhoun, S.L. (2011). Impact of IQ, age, SES, gender, and race on autistic symptoms. Research in Autism Spectrum Disorders, 5, 749-757. doi:

10.1016/j.rasd.2010.09.002

Owens, L.A. (2011). Self-determination in the employment first movement. National Gateway to Self-Determination, 2, 30-31. Retrieved from http://www.ngsd.org/. 
Ozonoff, S., South, M., \& Miller, J.N. (2000). DSM-IV-defined Asperger syndrome: Cognitive, behavioral and early history differentiation from high-functioning autism. Autism, 4(1), 29-46.

Peacock, G., Amendah, D., Ouyang, L., \& Gross, S.D. (2012). Autism spectrum disorders and health care expenditures: The effects of co-occurring conditions. Journal of Developmental and Behavioral Pediatrics, 33, 2-8. http://dx.doi.org/10.1097/DBP.0b013e31823969de

Saunders, B.S., Tilford, J.M., Fussell, J., Schulz, E.G., Casey, P.H., \& Kuo, D.Z. (2015). Financial and employment impact of intellectual disability on families of children with autism. Families, Systems, \& Health, 33(1), 36-45. http://dx/doi.org/10.1037.fsh0000102

Taylor, J.L, Smith, L.E., \& Mailick, M.R. (2014). Engagement in Vocational Activities Promotes Behavioral Development for Adults with Autism Spectrum Disorders. Journal of Autism and Developmental Disorders, 44(6), 1447-1460.

Taylor, J.L., \& Seltzer, M.M. (2011). Employment and post-secondary educational activities for young adults with autism spectrum disorders during the transition to adulthood. Journal of Autism and Developmental Disorders, 41, 566-574.

Thomas, K. C., Ellis, A. R., McLaurin, C., Daniels, J., \& Morrissey, J. P. (2007). Access to care for autism-related services. Journal of Autism and Developmental Disorders, 37, 1902-1912.

Trainor, A. A., Morningstar, M. E., \& Murray, A. (2015). Characteristics of transition planning and services for students with high-incidence disabilities. Learning Disability Quarterly, 39(2), 113-124. https://doi.org/10.1177/0731948715607348 
United States Department of Agriculture. (2016). National school lunch

program. Retrieved from http://www.fns.usda.gov/nslp/national-school-lunchprogram-nslp

United States Department of Health and Human Services, Health Resources and Services Administration, Maternal and Child Health Bureau. (2013). The National Survey of Children with Special Health Care Needs Chartbook 2009-2010. Rockville, MD: U.S. Department of Health and Human Services.

Wehman, P., Sima, A. P., Ketchum, J., West, M. D., Chan, F., \& Luecking, R. (2014). Predictors of successful transition from school to employment for youth with disabilities. Journal of Occupational Rehabilitation, 25(2), 323-334. https://doi.org/10.1007/s10926-014-9541- 


\section{SECTION FIVE:}

AN ARTICLE FOR SUBMISSION TO THE JOURNAL OF SPECIAL EDUCATION 
Section Five: An Article for Submission to the Journal of Special Education

\begin{abstract}
In this study, the author examined the relation between postsecondary outcomes for students with Autism Spectrum Disorder related to three predictors - low socioeconomic status, presence of multiple disabilities, and participation in a communitybased work experience program while in high school. Participants were 45 students with an educational diagnosis of Autism Spectrum Disorder, who graduated from a public self-contained special education high school between the years of 2014 and 2017. Chi square analysis for each predictor indicated no statistically significant relationship between each variable and postsecondary outcome. Implications for research and practice are discussed.
\end{abstract}

Keywords: autism spectrum disorders, postsecondary outcomes, socioeconomic status, community-based work experiences, individualized education program, self-contained school

\title{
Introduction
}

Over the past three decades, the United States government has advocated for the success of individuals with disabilities in the workplace, creating and implementing many initiatives to support the needs of this population. In 2014, Congress passed the Workforce Innovation and Opportunity Act (WIOA), a bill whose goal is to update and improve the nation's workforce development system (Education and Workforce Committee of the United States House of Representatives, 2014). The implementation of WIOA in 2015 placed further stipulations on services and supports for youth with disabilities as they enter the workforce (The Arc, 2015). Specifically, regarding 
individuals with disabilities, WIOA's intended goal is to provide job search, placement assistance, career counseling skills training, and other supportive services for individuals with disabilities (Marquette, 2016).

Despite all this perceived governmental support, youth with disabilities struggle to find and/or maintain employment (Roux, Shattuck, Cooper, Anderson, Wagner, \& Narendorf, 2013). Over 36\% of youth with a disability between the ages of 16 and 19 were unemployed in 2016 (The United States Department of Labor, 2016). Further, over $17 \%$ of youth with disabilities between the ages of 20 and 24 were unemployed (The United States Department of Labor, 2016). These statistics sound low, but when compared to the unemployment rates of youth without disabilities, the difference is staggering. Only $15.8 \%$ of youth without disabilities between the ages of 16 and 19 reported unemployment. The number decreased further to $8.1 \%$ for youth between the ages of 20 and 24 (United States Department of Labor, 2016).

Still, these numbers do not tell the whole story for youth with disabilities. Young adults for whom disabilities impact communication and social interactions find barriers to postsecondary success varied in both type and severity. Thus, postsecondary success looks different for every youth with a disability. Yet, U.S. policy continues to focus only on employment opportunities for youth with disabilities (Fabian, Simonsen, Deschamps, \& Luecking, 2016).

\section{A Growing Need}

The US Department of Education (2011) reports that of the 6,608,446 special education youths, $10 \%$ are between the ages of 14 and 21 . Data suggests that, over the last decade, the prevalence of Autism Spectrum Disorder (ASD) diagnoses has increased 
by 11\%, 1 in 68 children (Centers for Disease Control, 2016; Holwerda, et al., 2013; Manning-Courtney, Murray, Currans, Johnson, Bing, Kroeger-Geoppinger, Sorenson, Bass, Reinhold, Johnson, \& Messerschmidt, 2013; Tchaconas \& Adesman, 2013). Persons with ASD display common behavioral characteristics including "communication deficits, social skill deficits, and restricted, repetitive, and stereotyped patterns of activities, interests, and behaviors" (Schall \& McDonough, 2010, p. 82). As the population with ASD prepare to enter adolescence and young adulthood, it is vital that their specific needs are considered when planning postsecondary goals.

Many of the evidence-based practices common among ASD programs target on children between the ages of three and six years (Schall, Wehman, \& McDonough, 2012). Scholars and practitioners have only recently begun to recognize that ASD is a lifelong disability with impairments that can significantly impact quality of life throughout adulthood (Taylor, Smith, \& Mailick, 2014). Research on young adults with ASD is limited, and little is known about factors that may help to promote positive adult development for those with ASD (Taylor, et al., 2014). Although some literature suggests that the symptoms of ASD decrease as age increases, research is still sparse regarding the impact of symptoms for older persons with ASD (Church \& Coplan, 1995; Schopler, Van Bourgondien, Wellman, \& Love, 2010; Taylor, et al., 2014). A large body of research exists regarding needs of students with disabilities to be successful as they transition from school to work, yet little is known regarding predictors of postsecondary success outcomes for the population of students with ASD. This study takes a closer look at three possible predictors and their influence on the postsecondary outcomes of those students with ASD specifically. 


\section{Self-Contained Schools}

Many of the employment training and transition supports provided to students with disabilities exist in a typical public education environment. That is, students with disabilities are included in the general education curriculum and environment per inclusive education guidelines. However, those students with more high needs disabilities, like ASD, often require self-contained programs to meet their educational needs. Self-contained schools or programs exist entirely separate from the general education population and have a specialized curriculum to meet the needs of students with intensive disabilities. In this study, data collected was from students with disabilities who attended a special education self-contained school. Students received all special education and related services in educational programs at these sites (Missouri Department of Elementary and Secondary Education - FAQs, 2017). A theoretical benefit of self-contained classrooms is their ability to provide high levels of these small group and one-to-one arrangements to meet student need while increasing student engagement (Logan \& Keefe, 1997). However, participating in these self-contained programs can sometimes limit or eliminate students' opportunities for experiences in real-life work environments due to their specialized nature.

Currently, little research exists regarding employment outcomes of these students who participate in employment training programs and other transition supports while enrolled in self-contained special education schools. However, WIOA's (2014) goals are geared specifically towards either full or part-time employment for all individuals with disabilities, including those with the most significant disabilities (Marquette, 2016). The 
present study examines predictors that may signify postsecondary success for students with ASD who have participated in secondary self-contained schools.

\section{The Role of Socioeconomic Status}

Research often cites family support as an indicator for employment success for those students with ASD (Benz, et al., 1996; Bellman, Burgstahler, \& Ladner, 2014; Gragoudas, 2014; Trainor, Morningstar, \& Murray, 2015; Wehman, Sima, Ketchum, West, Chan, \& Leucking, 2014). Additionally, current research reports that, for youth with disabilities to be successful in finding and maintaining employment, many outside supports are necessary, including financial supports (Holwerda, van der Klink, de Boer, Groothoff, \& Brouwer, 2013; Saunders, Tilford, Fussell, Schulz, Casey, \& Kuo, 2015). The likelihood of families with children with ASD experiencing financial strain is great (Buescher, Cidav, Knapp, \& Mandell, 2014; Saunders, et al., 2015).

Students with ASD often require more intensive educational supports, including additional supportive services outside the school environment such as behavioral therapy, physical therapy, speech therapy, and childcare. For caregivers, the monetary and time costs of these services add up quickly. Some literature suggests that the cost of caring for a person with ASD during his/her lifetime is an estimated \$1.4 million in the United States (Buescher, et al., 2014). As a result, many families of children with ASD and other disabilities rely on state and federally funded services, such as Medicaid waiver services and Supplemental Security Income (SSI), but not all supportive services are covered through these programs (Saunders, et al., 2015). Some services may even require partial or complete funding from individuals, families, or caregivers, creating an additional 
monetary burden for those households already experiencing financial stress (Mayes \& Calhoun, 2011).

Because of these added expenses, families often incur financial hardships, such as job loss, and limited employability, making accessing outside supportive services difficult (Cidav, Marcus, \& Mandell, 2012; Liptak, Benzoni, Mruzek, Nolan, Thingvoll, Wade, \& Fryer, 2008; Saunders, et al., 2015; Thomas, Ellis, McLaurin, Daniels, \& Morrissey, 2007). Lack of financial supports often causes added stress to families, which, in turn, creates elevated symptoms of those children with ASD, creating a detrimental cycle within the household, impacting not only caregivers, but individuals with disabilities' opportunities for success as well. (Mayes \& Calhoun, 2011). Households experiencing financial stress may also lack the resources to implement stressrelieving activities, such as childcare, entertainment, or family vacations, resulting in decreased coping skills for caregivers (Mayes \& Calhoun, 2011).

It is that those students with ASD and multiple disabilities require more intensive supports as they transition to life after high school (Mayes \& Calhoun, 2011; Saunders, et al., 2015). The cost of these programs and supports is high, placing them out of reach for many financially strapped families or caregivers (Liptak, et al., 2008; Mayes \& Calhoun, 2011; Thomas, et al., 2007). Research has not addressed the long-term impact of limited financial household resources on students with ASD as they navigate the increasingly complicated world of work after high school. For the purposes of this study, low socioeconomic status students are students who qualify for the National School Lunch Program (United States Department of Agriculture, 2016). This broad scale issue is one 
that needs to be further explored so that programs and supportive services can adequately address the holistic needs of those with ASD or multiple disabilities and their families.

\section{Are Community-Based Work Experiences Helpful?}

As more is learned about ASD and other disabilities, a shift in the research focus is beginning to emerge. Current studies have begun to focus on real-world activities to continue education while at the same time developing work skills that are easily transferable to the postsecondary world of work, indicating a shift in thinking that participation in work experiences during high school promotes employability of students with disabilities (Bellman, et al., 2014; Gragoudas, 2014; Owens, 2011; Wehman, et al., 2014). Focusing on employment skills flips the conversation away from the previous academic focus of special education programming related to postsecondary success.

While legislation regarding transition for students with disabilities has always focused on outcomes, activities, student preferences and interests, and stakeholder involvement (Kohler, 1996). More recently, it has begun to emphasize the need for the development of employment skills along with community experiences to aid in a smooth transition from school to post school activities (Kohler, 1996; IDEA, 2004). In fact, The Individuals with Disabilities Education Act's (IDEA) (2004) standards closely align with the goals of many community-based work experience (CBWE) programs provided in special education schools.

One facet of Kohler's (1996) model, structured work experiences paired with student participation in individual level planning, has been shown to be effective in preparing students with disabilities for postsecondary transitions (Kohler, 1996). Participation in employment training in the classroom or school community is one 
demonstrated factor that appears to increase the likelihood that youth with disabilities will be successful in meeting goals after graduation (Gragoudas, 2014; Kohler, 1996; Owens, 2011; Wehman, et al., 2014). Additionally, CBWE programs have been shown to increase skills areas that students with ASD typically lack, such as communication, problem solving, and self-confidence while also promoting motivation, job-related skills, relationship building, and self-advocacy (Bellman, et al., 2014; Kohler, 1996; Wehman, et al., 2014). For this study, CBWE represent experiences that may include in-school or after school opportunities, or experiences outside the traditional school setting (including internships), that are provided in an integrated environment to the maximum extent possible (Education and Workforce Committee of the United States House of Representatives, 2014).

\section{Co-occurring Disabilities}

As research regarding ASD continues, it finds that a significant portion of the population of those diagnosed with ASD is also diagnosed with a second disability, such as genetic syndromes or psychiatric disorders (Saunders, et al., 2015; Taylor, et al., 2014). For example, a significant portion of those diagnosed with ASD also have a diagnosis of Intellectual Disability (ID; Peacock, Amendah, Ouyang, \& Gross, 2012; Saunders, et al., 2015; U.S. Department of Health and Human Services, Health Resources and Services Administration, Maternal and Child Health Bureau, 2013). A secondary disability diagnosis can often result in compounded difficulties for students already facing significant challenges, both in the school and home environments, as well as the transition into the community post-graduation (Saunders, et al., 2015). With the increasing push from the American government for employment for all, it is clear that 
this population will encounter added challenges. Research indicates that those with cooccurring disabilities are less likely to be employed than those with a singular diagnosis of ASD (Taylor \& Seltzer, 2011).

As it stands, little research exists on the postsecondary success rates for those with multiple disabilities, including ASD. Research is needed to determine how these cooccurring disabilities impact the ability of students to obtain employment after graduation, as well as what supports may be needed to ensure maintenance of employment once attained. This study aims to further the investigation that is clearly needed to determine the growing needs of individuals with ASD and establish programs that can adequately support the needs of this population after graduation.

Conceptually, this study follows Kohler's (1996) model for transition programming links transition theory with transition practice. Additionally, the framework of this research study is driven by the current legislative stipulations of The IDEA (2004). Thus, transition planning should be the foundation from which educational programs and activities are developed (Kohler, 1996). Both IDEA (2004) and Kohler (1996) focus on the role of the student as an active participant in the transition planning processing, ensuring that their needs are the focus of all programs, planning, and activities. To achieve student success after graduation, regarding employment or any other arena, schools and program must promote activities that focus on the student's individual abilities, needs, and goals (Kohler, 1996). This study attempts to encompass a somewhat holistic approach to Kohler's theory by exploring three separate variables that may impact postsecondary success to create programming that encompasses the needs of the student in all environments. 
While it seems apparent the high school work experiences may benefit students with ASD as they transition to life after high school, there are still many unanswered questions. What additional supports, if any, ensure postsecondary success for students with ASD? What do postsecondary outcomes look like for students with ASD whose needs prevent them from participating in a traditional academic curriculum or school setting? Are students with co-occurring disabilities able to obtain postsecondary success? In this study, specific factors were analyzed for their impact on the postsecondary outcomes of students with an educational diagnosis of Autism Spectrum Disorder. There were three research questions:

1) What is the impact of participation in a Community-Based Work Experiences (CBWE) program during high school on postsecondary success as defined by the Graduate Six Month Follow Up questionnaire for students with Autism Spectrum Disorder who attended a self-contained secondary special education school between the academic years of 2013-14, 2014-15, 2015-16, and 2016-17?

2) What is the impact of socioeconomic status (SES), as defined by qualification for Free and Reduced Lunch programs, on postsecondary success as defined by the Graduate Six Month Follow Up questionnaire for students with Autism Spectrum Disorder who attended a self-contained special education secondary school between the academic years of 2013-14, 2014-15, 2015-16, and 2016-17?

3) What is the impact of a secondary disability diagnosis on postsecondary success as defined by the Graduate Six Month Follow Up questionnaire for students with Autism Spectrum Disorder who attended a self-contained secondary special 
education school between the academic years of 2013-14, 2014-15, 2015-16 and 2016-17?

\section{Method}

Pearson's Chi Square test was utilized to determine the potential effect of each variable on postsecondary outcomes. Chi Square provides versatility in summarizing the relationship between two discrete, categorical variables (Field, 2013). A log-linear analysis was calculated, determining the relationship between the three predictors for this study (Tabachnick \& Fidell, 2007).

\section{Participants}

Archival data were collected from a public special education school district. Its boundaries cover a large county of over 500 square miles, located near a large metropolitan area. The district contracts with all 22 public school districts within the county to provide special education services to nearly 25,000 students with disabilities.

Only students who attended the district's three secondary self-contained special education high schools were considered. Each of these self-contained high schools incorporates a CBWE program for students ages 18-21. Levels of CBWE participation vary, based on the abilities and needs of the individual student. CBWE may take place within the school community or the community within a five-mile radius of each school. Students who graduated from the district's three self-contained high schools between 2014 and 2017, with an educational diagnosis of ASD were included in the study. Additional information gathered included students' postsecondary outcomes six months post-graduation, students' qualification for free and reduced lunch, participation in CBWE programs, and the presence of additional disability diagnoses. There were a total 
of 70 graduates who met the criteria for this study (25 in 2014, 11 in 2015, 22 in 2016, and 12 in 2017). Of these 70 graduates, 35 met their postsecondary goals, 32 qualified as low socioeconomic status, as determined by their qualification for the free and reduced lunch program, 23 had a co-occurring disability, and 45 participated in a CBWE program during high school.

\section{Procedures}

All data was collected electronically via the school district's archival database. Information regarding student postsecondary employment outcomes is collected by district employees six months after the student's graduation date using an electronic Graduate Six Month Follow Up questionnaire (Appendix A) and stored in the district's secure database. Data provided by the district included student qualification for the free and reduced lunch program, student educational diagnosis, additional disability diagnoses per information provided by the students' individual educational plan (IEP), and student results of the Graduate Six Month Follow Up questionnaire.

\section{Data Analysis}

Due to the categorical nature of the data set as well as the limited sample size, the effect of each predictor variable was analyzed using Pearson's Chi Square test. Postsecondary outcomes were compared between two groups of students with ASD those who did participate in CBWE and those who did not. Postsecondary outcomes were also compared between a second grouping of students - those who qualified as low SES students and those who did not. The third comparison of postsecondary outcomes of two student groups also took place between those students with a diagnosis of ASD and those 
students who had multiple disability diagnoses, one of which is ASD. A log-linear analysis was used to determine if a relationship between the three variables exists.

\section{Findings}

This study aims to deepen the understanding of the impact of CBWE programs, economic hardship, and multiple disabilities on postsecondary success for those with ASD. Generally, the findings of this study reveal mixed results.

\section{Participation in CBWE}

CBWE programs have long advocated that their implementation promotes long term success for those with ASD and other disabilities by providing real world skill acquisition and training opportunities. Findings of this study were unable to reject the null hypothesis, leaving program stakeholders unsure if their efforts are achieving the desired impact. Pearson's Chi Square test was performed to examine the relationship between participation in CBWE and postsecondary outcomes of students with ASD. There was not a statistically significant association between participation in CBWE and postsecondary outcomes for students with ASD, $\chi^{2}(1)=0.560, p>.01$.

\section{Low Socioeconomic Status}

Findings were unable to reject the null hypothesis that low SES impacted the postsecondary success of students with ASD. This study suggests that those with ASD may be on equal footing related to postsecondary success regardless of economic constraints. Pearson's Chi Square test was performed to examine the relationship between SES and postsecondary outcomes of students with ASD. There was not a statistically significant association between low SES and postsecondary outcomes for students with $\operatorname{ASD} \chi^{2}(1)=0.921, p>.01$ 


\section{Multiple Disability Diagnoses}

Persons with ASD coupled with an additional disability diagnosis often encounter compounded challenges when seeking to reach their goals following graduation. This study provides unclear results as to how these multiple diagnoses truly impact this population's ability to succeed after graduation from high school. Pearson's Chi Square test was performed to examine the relationship between multiple disability diagnoses and postsecondary outcomes of students with ASD. There was not a statistically significant association between diagnoses of multiple disabilities and postsecondary outcomes for students with ASD, $\chi^{2}(1)=0.583, p>.01$, therefore, the null hypothesis was unable to be rejected.

\section{Low SES, Participation in CBWE, and Multiple Disability Diagnosis}

In the real world, the variables examined within this research can often be interconnected. However, within the confines of this study, it was determined that none of the variables had a significant impact on each other as to potentially affect outcomes. The three-way log-linear analysis produced a likelihood ratio that was $\chi^{2}(0)=0, p=1$. The analysis indicated that the highest-order interaction (low SES x participation in $C B W E \times$ multiple disability diagnosis) was not significant, $\chi^{2}(1)=.813, \mathrm{p}<.01$. K-Way and Higher Order Effects indicated that removing the one-way effects and any higherorder effects is not significant $\chi^{2}(1)=.027, \mathrm{p}<.01$. Overall, the combined effect of the variables and interactions is not significant.

\section{Discussion}

This study was designed to determine predictors that impact postsecondary outcomes for students with ASD. Differences were explored in terms of socioeconomic 
status, multiple disability diagnoses, and participation in CBWE. Though past research has theorized an impact of each of the three predictor variables on postsecondary outcomes, results of this study indicated that no significant relationship exists between any of the three variables explored and postsecondary outcomes of students with ASD.

One limitation of this study was sample size. At the time of this study, the district had only recently begun to collect postsecondary outcome data electronically. Obtaining a sufficient sample size of at least 30 students, data included four academic years, 20142017. Data collected included graduates of all three self-contained special education secondary school sites to ensure the largest sample size possible. Despite this, the sample size yielded only 70 who fit the criteria outlined in this study. Future studies should consider collecting longitudinal data to support consistency among cohorts and allow researchers to pinpoint influencing variables with more precision.

A second limitation is students' qualification for free and reduced lunch. The school district featured in this study is not the district that determines eligibility. The determination comes from the student's home district. However, some districts, due to the SES of the community they serve, automatically qualify all students for free and reduced lunch upon enrollment. Some research indicates that, due to the intensive needs of this population, many families of children with ASD experience financial strain and limited access to supportive services needed to ensure postsecondary success (Cidav, Marcus, \& Mandell, 2012; Mayes \& Calhoun, 2011; Saunders, et al., 2015). However, results of this study indicate that low SES may not have an impact on postsecondary outcomes for students with ASD. As previously mentioned, many families receive direct support services throughout their child's lifetime through publicly funded programs, such 
as Medicaid waiver services and Supplemental Security Income (SSI). These programs are needs based, so families with lower incomes often qualify for more supports. Additionally, past research has indicated that using free and reduced lunch qualification is not always an accurate representation of household SES (Harwell \& LeBeau, 2010). Future research could include household income, number of dependents in the household, and other factors when assessing SES for graduates and their families to gain a more accurate perspective of how this factor may impact postsecondary outcomes (Harwell \& LeBeau, 2010).

A third factor that may have impacted the outcome of the analysis was the use of discrete data. ASD has long been categorized as a spectrum disorder, meaning that the range of the impact of the disability on level of functioning varies by individual (Ozonoff, South, \& Miller, 2000). The definition of ASD has continually evolved over the past 50 years and will likely continue to do so as more is learned about the disability (Hassall, 2017). Furthermore, there is no clear determination of how ASD, or any disability, will affect an individual's level of functioning (Ozonoff, et al., 2000). Although there is no doubt that those with ASD and other disabilities will encounter obstacles as they transition from school to the adult world, this study seems to indicate that the impact may not be as significant as past research seems to indicate. Also, by categorizing participants in a simple yes/no fashion, full impact of the disability may not have been realized within this study. In this study, the yes/no categorization does not consider other possible influencing factors, such as IQ, academic proficiency, or goal achievement prior to graduation, to name a few. These factors should be considered in 
future research opportunities regarding the population with ASD in self-contained schools.

Researchers must also consider the measures by which postsecondary outcome data is collected. The Graduate Six Month Follow up is a district-created tool, potentially limiting its reliability and validity. Graduate data is collected by many different employees of the school district, allowing for some subjectivity in the interpretation of whether or not postsecondary goals have been met. For example, there is a potential for bias to occur in the recording of the data if the collector has a relationship with the graduate's family. The school district and future researchers should consider fully exploring the tool used to gather data as well as ways to preserve objectivity during data collection.

The time frame at which data is collected should also be considered. The district in this study is a unique district in the comprehensive services it can provide to the special education population. However, community resources that are accessible to graduates after high school are not parallel in the quality or quantity of their services. Often, programs are full or funding is limited, placing graduates on wait lists for programs and services after graduation. If data was considered further into the future after graduation, at one year or two years, postsecondary outcomes might look entirely different. For example, students who were previously on waiting lists for programs during the Graduate Six Month Follow Up data collection period may be participating in programs at the one or two-year mark, effectively meeting their postsecondary goals. The district, along with future researchers should consider collecting data at longer time 
intervals to obtain a better assessment of the potential impact of variables explored in this study.

\section{Implications for Practice}

Study results serve as a resource for special education school practitioners, policymakers, and community agencies considering how to best support students with ASD as they transition into the community following graduation. Although data analysis did not reveal a statistically significant impact, past theory has indicated that each of the factors considered has the potential to impact individual students with ASD. As a practitioner, it will be important to consider each of these variables and their potential impact on policy and practice as they are continually created and modified to meet the evolving needs of students with ASD.

As the district evaluates its current CBWE program, it cannot discount past research regarding the effectiveness of $\mathrm{CBWE}$ programs on postsecondary transitions (Bellman, et al., 2014; Gragoudas, 2014; Kohler, 1996; Lindstrom, Paskey, Dickinson, Doren, Zane, \& Johnson, 2007; Owens, 2011; Wehman, et al., 2014). However, it will be important how this research is interpreted and utilized. Because the degree of severity of which ASD impacts the student's functioning can vary, a flexible CBWE program that is

able to meet their individualized needs must be created. Data indicated that only $64.3 \%$ of graduates with ASD participated in a CBWE program. If the district's goal is postsecondary success for all, CBWE programs need to be designed to include all students at all levels of functioning. The district's CBWE program exists in a selfcontained environment, allowing practitioners a unique opportunity to create a more intensive community integration program, further paving the way for a smooth transition 
into adulthood for students with ASD. This study serves as a starting point for practitioners, policy-makers, and other key stakeholders, to question the importance of key factors emphasized in past research to positively impact the futures of students with ASD. With these aspects in mind, practitioners must evaluate current CBWE programs with a critical eye to ensure the needs of all students with ASD are met, both in schools and as they transition into their next phase of life.

\section{Declaration of Conflicting Interests}

The researcher is an employee of the school district and is one of the staff members responsible for conducting the Graduate Six Month Follow Up each year. Bias was avoided by requesting data to be aggregated and scrubbed of all identifying information prior to access by the researcher. Confidentiality was preserved by assigning random numbers to participants to avoid transferring identifying information.

\section{Funding}

The author received no financial support for the research, authorship, and/or publication of this article. 


\section{References}

Bellman, S., Burgstahler, S., \& Ladner, R. (2014). Work-based learning experiences help students with disabilities transition to careers: A case study of university of Washington projects. Work, 48, 399-405. https://doi.org/10.3233/WOR-131780

Benz, M.R., Yovanoff, P, \& Doren, B. (1997). School-to-work components that predict postschool success for students with and without disabilities. Exceptional Children, 63(2), 151-165.

Buescher, A.V., Cidav, Z., Knapp, M., \& Mandell, D.S. (2014). Costs of autism spectrum disorders in the United Kingdom and the United States. Journal of the American Medical Association Pediatrics, 168, 721-728.

http://dx.doi.org/10.1001/jamapediatrics.2014.210

Centers for Disease Control and Prevention. (2016). Prevalence of autism spectrum disorders_-Autism and developmental disabilities monitoring network, United States, 2008. Morbidity and Mortality Weekly Report (MMWR), 61(SS03), 1-19.

Church, C.C., \& Coplan, J. (1995). The high-functioning autistic experience: Birth to preteen years. Journal of Pediatric Health Care, 9, 22-29.

Cidav, Z, Marcus, S.C., \& Mandell, D.S. (2012). Implications of childhood autism for parental employment and earnings. Pediatrics, 129, 617-623. http://dx.doi.org/10.1542/peds.2011-2700

Education and Workforce Committee of the United States House of Representatives (2014). Congress passes WIOA: Overhaul of America's job training programs 
headed to president's desk following strong bipartisan support from Congress. Retrieved from: http://mawd.us/congress-passes-wioa/

Fabian, E., Simonsen, M., Deschamps, A., \& Luecking, D. M. (2016). Service System Collaboration in Transition: An Empirical Exploration of its Effects on Rehabilitation Outcomes for Students with Disabilities, 82(3), 3-10.

Field, A. (2013). Discovering statistics using IBM SPSS statistics ( ${ }^{\text {th }}$ Ed.). Thousand Oaks, CA: Sage.

Gragoudas, S. (2014). Preparing students with disabilities to transition from school to work through self-determination training. Work, 48(3), 407-411. https://doi.org/10.3233/WOR-131782

Harwell, M. \& LeBeau, B. (2010). Student eligibility for free and reduced lunch as an SES measure in education research. Educational Researcher, 39(2), 120-131.

Holwerda, A., van der Klink, J.J.L., de Boer, M.R., Groothoff, J.W., \& Brouwer, S. (2013). Predictors of sustainable work participation of young adults with developmental disorders. Research in Developmental Disabilities, 34, 2753-2763.

Individuals with Disabilities Education Act. (2004). 20 USC chapter 22, subchapter II: Assistance for education of all children with disabilities. Retrieved from http://uscode.house.gov/view.xhtml?path=/prelim@ @itle20/chapter33/subc hapter2\&edition=prelim 
Individuals with Disabilities Education Act. (2004). Transition services. Retrieved from: https://sites.ed.gov/idea/regs/b/a/300.43

Kohler, P.D. (1996). A taxonomy for transition programming: linking research and practice. Washington, DC: U.S. Department of Education, Office of Educational Research and Improvement.

Lindstrom, L., Paskey, J., Dickinson, J., Doren, B., Zane, C., \& Johnson, P. (2007). Voices from the field: Recommended transition strategies for students and staff. Journal for Vocational Special Needs Education, 29(2), 4-15.

Liptak, G.S., Benzoni, L.B., Mruzek, D.W., Nolan, K.W., Thingvoll, M.A., Wade, C.M., Fryer, G.E. (2008). Disparities in diagnosis and access to health services for children with autism: Data from the National Survey of Children's Health. Journal of Developmental and Behavioral Pediatrics, 29, 152-160.

Logan, K.R., \& Keefe, E.B. (1997). A comparison of instructional context, teacher behavior, and engaged behavior for students with severe disabilities in general education and self-contained elementary classrooms. Journal of the Association for Persons with Severe Handicaps, 22(1), 16-27.

Manning-Courtney, P., Murray, D., Currans, K., Johnson, H., Bing, N., KroegerGeoppinger, K., Sorenson, R., Bass, J., Reinhold, J., Johnson, A., \& Messerschmidt, T. (2013). Autism spectrum disorders. Current Problems in Pediatric and Adolescent Health Care, 43(1), 2-11.

Marquette, B. Y. J. (2016). Workforce innovation and opportunity for youth with ASD and developmental disabilities. Exceptional Parent, 46(10), 25-28. 
Mayes, S.D. \& Calhoun, S.L. (2011). Impact of IQ, age, SES, gender, and race on autistic symptoms. Research in Autism Spectrum Disorders, 5, 749-757. doi: 10.1016/j.rasd.2010.09.002

Missouri Department of Elementary and Secondary Education. (2017). FAQs. Retrieved from: https://dese.mo.gov/faqs

Owens, L.A. (2011). Self-determination in the employment first movement. National Gateway to Self-Determination, 2, 30-31. Retrieved from http://www.ngsd.org/.

Ozonoff, S., South, M., \& Miller, J.N. (2000). DSM-IV-defined Asperger syndrome: Cognitive, behavioral and early history differentiation from high-functioning autism. Autism, 4(1), 29-46.

Peacock, G., Amendah, D., Ouyang, L., \& Gross, S.D. (2012). Autism spectrum disorders and health care expenditures: The effects of co-occurring conditions. Journal of Developmental and Behavioral Pediatrics, 33, 2-8. http://dx.doi.org/10.1097/DBP.0b013e31823969de

Roux, A.M., Shattuck, P.T., Cooper, B.P., Anderson, K.A., Wagner, M., \& Narendorf, S.C. (2013). New research: Postsecondary employment experiences among young adults with an autism spectrum disorder. Journal of the American Academy of Child \& Adolescent Psychiatry, 52, 931-939. doi: 10.1016/j.jaac.2013.05.019

Saunders, B.S., Tilford, J.M., Fussell, J., Schulz, E.G., Casey, P.H., \& Kuo, D.Z. (2015). Financial and employment impact of intellectual disability on families of children with autism. Families, Systems, \& Health, 33(1), 36-45. http://dx/doi.org/10.1037.fsh0000102 
Schall, C. \& McDonough, J.T. (2010). Autism spectrum disorders in adolescence and early adulthood: characteristics and issues. Journal of Vocational Rehabilitation, $32,81-88$.

Schall, C., Wehman, P., \& McDonough, J.L. (2012). Transition from school to work with students with autism spectrum disorders: understanding the process and achieving better outcomes. Pediatric Clinics of North America, 59, 189-202.

Schopler, E., Van Bourgondien, M.E., Wellman, G.J., \& Love, S.R. (2010). ( ${ }^{\text {nd }}$ Ed.). Childhood Autism Rating Scale. Los Angeles: Western Psychological Services.

Tabachnick, B.G. \& Fidell, L.S. (2007). Using multivariate statistics ( $5^{\text {th }}$ Ed.). Boston, MA: Pearson Education.

Taylor, J.L, Smith, L.E., \& Mailick, M.R. (2014). Engagement in Vocational Activities Promotes Behavioral Development for Adults with Autism Spectrum Disorders. Journal of Autism and Developmental Disorders, 44(6), 1447-1460.

Taylor, J.L., \& Seltzer, M.M. (2011). Employment and postsecondary educational activities for young adults with autism spectrum disorders during the transition to adulthood. Journal of Autism and Developmental Disorders, 41, 566-574.

Tchaconas, A., \& Adesman, A., (2013). Autism spectrum disorders: A pediatric overview and update. Current Opinion in Pediatrics, 25(1), 130-144.

The Arc (2015). WIOA: What it means for people with intellectual and/or developmental disabilities. The Arc: National Policy Matters. Retrieved from: http://www.thearc.org/document.doc?id=5183 
Thomas, K. C., Ellis, A. R., McLaurin, C., Daniels, J., \& Morrissey, J. P. (2007). Access to care for autism-related services. Journal of Autism and Developmental Disorders, 37, 1902-1912.

Trainor, A. A., Morningstar, M. E., \& Murray, A. (2015). Characteristics of transition planning and services for students with high-incidence disabilities. Learning Disability Quarterly, 39(2), 113-124. https://doi.org/10.1177/0731948715607348

United States Department of Agriculture. (2016). National school lunch program. Retrieved from http://www.fns.usda.gov/nslp/national-school-lunch-program-nslp

United States Department of Education (2011). Statement by Assistant Secretary Alexa Posny on the Fourth Annual World Autism Awareness Day. Retrieved from: www.ed.gov/news/press-releases/statement-assistant-secretary-alexa-posnyfourth-annual-world-autism-awareness-d.

United States Department of Health and Human Services, Health Resources and Services Administration, Maternal and Child Health Bureau. (2013). The National Survey of Children with Special Health Care Needs Chartbook 2009-2010. Rockville, MD: U.S. Department of Health and Human Services.

United States Department of Labor (2016). Office of disability employment policy: Monthly youth labor force participation rate and unemployment rate. Retrieved from: https://www.dol.gov/odep/stats/index.htm

Wehman, P., Sima, A. P., Ketchum, J., West, M. D., Chan, F., \& Luecking, R. (2014). Predictors of successful transition from school to employment for youth with 
disabilities. Journal of Occupational Rehabilitation, 25(2), 323-334.

https://doi.org/10.1007/s10926-014-9541- 


\section{SECTION SIX:}

SCHOLARLY PRACTITIONER REFLECTION 


\section{Section Six: Scholarly Practitioner Reflection}

\section{Introduction}

The focus of the dissertation process is not only to foster new research, but to reflect upon that research while incorporating it into current practices as an educational leader. Over the past two years of coursework, I have been cultivating my own identity as a leader and a scholar during that process. Tichy (2009) remarks that 'creating your own Teachable Point of View, by identifying and reflecting upon the experiences that have shaped you' has the capability to produce better leaders. The experience of creating my own Teachable Point of View, by tying my own research with previous learning experiences to further define who I am as an educational leader and scholar, has been a profound experience. The dissertation process has truly given me a solid foundation to continue to evolve as an educational leader and scholar.

\section{Educational Leadership Practice}

Leadership in public education often focuses heavily on outcomes, both positive and negative, when effectively analyzing, creating, and implementing policy. My study encompassed variables that are outside of the control of the school environment, which forced me to explore how practitioners can account for these variables to effectively impart crucial life skills to students with disabilities as we prepare them for a world that is dramatically different from the one they find inside the classroom. This perspective is one that I will carry with me moving forward as a practitioner as my district attempts to bridge the gap from success at school to success in the post-graduation world for students with disabilities. 
The dissertation process has also shown me that, despite careful, capable investigation of the effect of current practice, sometimes the answers are ambiguous. Moving forward, it will be important to implement smart practices when implementing policy development and analysis (Bardach \& Patashnik, 2016). Researching what has worked for other districts, states, and countries may not always be the best fit for the students in my district. It will be crucial to continually evaluate new policy and practices with a critical eye to ensure time and resources are invested to provide the maximum benefit to students.

The dissertation process, as well as my professional experience, has further magnified that concept adult educators tend to look to one another rather than theory or the research community, for ideas, tips and techniques that work (Dirkx, 2006). When considering policy creation, one of the most important goals of public policy is to help others make good, well-informed decisions (Stone, 2012). I know now that this is part of my role as an educational leader. I can be an integral force, not only in educating my colleagues and administrators, but also in advocating for best practices for students when policies are created, even if the conversations are uncomfortable. Through this dissertation process, I have learned that to change, as an organization and an individual, we must experience that stress (Preskill \& Brookfield, 2009; Gill, 2010). Discomfort is necessary for change. As an educational leader, it is my role to ask those hard questions, to establish that the district is functioning outside of the mindset of 'that's the way it has always been done' and ensure that policy and practice is truly in the best interest of our students.

\section{Scholarly Development}


The dissertation process has shown me that future research is a means of not only supporting current students with disabilities, but also as a tool to influence the creation new policies or programs to meet the unique needs of my students to promote lifelong success. As a researcher who is also an employee of such a distinctive school setting, I have access to a wealth of archival data that has the potential, through research, to provide insight to districts across the country who are working with students with disabilities.

Much of the research literature throughout the dissertation process has provided me with a solid foundation upon which to not only initiate change within my own organization, but to increase the knowledge base for all stakeholders regarding students with high needs disabilities. By pursuing individual scholarship, I have developed an increased sense of self-awareness, which has allowed me to be more effective in my current position and will promote my continued learning in the future (Brookfield \& Preskill, 2009; Gill, 2010).

Additionally, I appreciate that learning is vital for both a leader and an organization. Without the drive to continually learn, organizations and individuals could not continue to improve, achieve goals, or reach new capacities (Gill, 2010). However, the learning must always be intentional to be truly beneficial (Gill, 2010). I have realized the vast number studies that are potentially completed each year with inconclusive results, yet, many times, only the studies who produce significant results are published. Further, just because a program or practice is widely researched and published does not always mean it will be the best fit for my unique student population. I recognize that no action is neutral or value free, even in the world of research (Bolman \& Deal, 2013; 
Kezar, Carducci, \& Contreras-McGavin, 2006). The dissertation process has not only allowed me to develop the tools for continuous learning, but has also heightened my awareness that it is my responsibility to constantly reexamine intentions to promote effective learning and change (Gill, 2010). As a result, I find myself examining current research with a more critical mindset.

\section{Conclusion}

My experiences throughout the dissertation process have not only reshaped my definition of leadership and scholarship, but have also affected who I am in those respects as well. I am grateful for the opportunities provided through this process as it has allowed me to learn how to capitalize on my strengths while at the same time promoting conscious, reflective growth. One of the most valuable experiences I have taken away from the dissertation process is that community is essential to leadership in any aspect. I believe I would not have been able to complete this process without the support of my community. This includes not only my colleagues, or family, but my fellow cohort members. At times, only my cohort could understand my frustration with SPSS or the feeling of accomplishment when I completed a section of the dissertation. The continuous process of learning from and being supported by one another is one that has truly impacted who I am as a leader (Gill, 2010). These collaborative experiences have created deeply meaningful transformative learning that will continue to impact who I am as a leader for the rest of my life (Hobbs \& Coiro, 2016). The relationships I have built with the individuals within my regional cohort are ones that will last well beyond the completion of this dissertation and I will be forever grateful for their support throughout this process. I truly believe that, armed with the foundation provided by this program, and the relationships I have developed along 
the way, I can enact change within my organization and become a dynamic leader within my field as well. 


\section{References}

Bellman, S., Burgstahler, S., \& Ladner, R. (2014). Work-based learning experiences help students with disabilities transition to careers: A case study of university of Washington projects. Work, 48, 399-405. https://doi.org/10.3233/WOR-131780

Benz, M.R., Yovanoff, P, \& Doren, B. (1997). School-to-work components that predict postschool success for students with and without disabilities. Exceptional Children, 63(2), 151-165.

Buescher, A.V., Cidav, Z., Knapp, M., \& Mandell, D.S. (2014). Costs of autism spectrum disorders in the United Kingdom and the United States. Journal of the American Medical Association Pediatrics, 168, 721-728.

http://dx.doi.org/10.1001/jamapediatrics.2014.210

Centers for Disease Control and Prevention. (2016). Prevalence of autism spectrum disorders-Autism and developmental disabilities monitoring network, United States, 2008. Morbidity and Mortality Weekly Report (MMWR), 61(SS03), 1-19.

Church, C.C., \& Coplan, J. (1995). The high-functioning autistic experience: Birth to preteen years. Journal of Pediatric Health Care, 9, 22-29.

Cidav, Z, Marcus, S.C., \& Mandell, D.S. (2012). Implications of childhood autism for parental employment and earnings. Pediatrics, 129, 617-623. http://dx.doi.org/10.1542/peds.2011-2700

Coryell, J. (2013). Collaborative, comparative inquiry and transformative crosscultural adult learning and teaching: A Western educator metanarrative and inspiring a global vision. Adult Education Quarterly, 63(4), 299-320. 
Crouch, E. (2016). School once meant isolation. Now an autistic graduate is 'the mayor' of Parkway West High. St. Louis Post-Dispatch. Retrieved from: http://www.stltoday.com/news/local/education/school-once-meant-isolation-now-anautistic-graduate-is-the/article_9cb22a49-99c8-5ed8-a352-1881f2ec589c.html

Education and Workforce Committee of the United States House of Representatives (2014). Congress passes WIOA: Overhaul of America's job training programs headed to president's desk following strong bipartisan support from Congress. Retrieved from: http://mawd.us/congress-passes-wioa/

Eisenman, L.T. (2007). Social networks and careers of young adults with intellectual disabilities. Intellectual and Developmental Disabilities, 45(3), 739-747.

Erbentraut, J. (2015). How these 4 major companies are tackling the autism unemployment rate. The Huffington Post. Retrieved from http://www.huffingtonpost.com/2015/05/07/autism-employment_n_7216310.html

Fabian, E., Simonsen, M., Deschamps, A., \& Luecking, D. M. (2016). Service System Collaboration in Transition: An Empirical Exploration of its Effects on Rehabilitation Outcomes for Students with Disabilities, 82(3), 3-10.

Field, A. (2013). Discovering statistics using IBM SPSS statistics ( $4^{\text {th }}$ Ed.). Thousand Oaks, CA: Sage.

Gill, S. J. (2010). Developing a learning culture in nonprofit organizations. Los Angeles: CA: Sage.

Gragoudas, S. (2014). Preparing students with disabilities to transition from school to work through self-determination training. Work, 48(3), 407-411. https://doi.org/10.3233/WOR-131782 
Harwell, M. \& LeBeau, B. (2010). Student eligibility for free and reduced lunch as an SES measure in education research. Educational Researcher, 39(2), 120-131.

Holwerda, A., van der Klink, J.J.L., de Boer, M.R., Groothoff, J.W., \& Brouwer, S. (2013). Predictors of sustainable work participation of young adults with developmental disorders. Research in Developmental Disabilities, 34, 2753-2763.

Hoover, A. (2016). The role of the community in transition to the adult world for students with disabilities. American Secondary Education, 44(2), 21-31.

Individuals with Disabilities Education Act. (2004). 20 USC chapter 22, subchapter II: Assistance for education of all children with disabilities. Retrieved from http://uscode.house.gov/view.xhtml?path=/prelim@title20/chapter33/subc hapter2\&edition=prelim

Individuals with Disabilities Education Act. (2004). Transition services. Retrieved from: https://sites.ed.gov/idea/regs/b/a/300.43

Kohler, P.D. (1996). A taxonomy for transition programming: linking research and practice. Washington, DC: U.S. Department of Education, Office of Educational Research and Improvement.

Lehmann, J., Bassett, D., Sands, D.J., Spencer, K., \& Gliner, J. (1999). Research translated into practice for increasing student involvement in transition-related activities. Career Development and Transition for Exceptional Individuals, 22, 2-19. 
Lindstrom, L., Paskey, J., Dickinson, J., Doren, B., Zane, C., \& Johnson, P. (2007).

Voices from the field: Recommended transition strategies for students and staff. Journal for Vocational Special Needs Education, 29(2), 4-15.

Liptak, G.S., Benzoni, L.B., Mruzek, D.W., Nolan, K.W., Thingvoll, M.A., Wade, C.M., Fryer, G.E. (2008). Disparities in diagnosis and access to health services for children with autism: Data from the National Survey of Children's Health. Journal of Developmental and Behavioral Pediatrics, 29, 152-160.

Logan, K.R., \& Keefe, E.B. (1997). A comparison of instructional context, teacher behavior, and engaged behavior for students with severe disabilities in general education and self-contained elementary classrooms. Journal of the Association for Persons with Severe Handicaps, 22(1), 16-27.

Manning-Courtney, P., Murray, D., Currans, K., Johnson, H., Bing, N., KroegerGeoppinger, K., Sorenson, R., Bass, J., Reinhold, J., Johnson, A., \& Messerschmidt, T. (2013). Autism spectrum disorders. Current Problems in Pediatric and Adolescent Health Care, 43(1), 2-11.

Marquette, B. Y. J. (2016). Workforce innovation and opportunity for youth with ASD and developmental disabilities. Exceptional Parent, 46(10), 25-28.

Mayes, S.D. \& Calhoun, S.L. (2011). Impact of IQ, age, SES, gender, and race on autistic symptoms. Research in Autism Spectrum Disorders, 5, 749-757. doi: 10.1016/j.rasd.2010.09.002

Merriam, S. B., \& Bierema, L. L. (2014). Adult learning: Linking theory and practice. San Francisco, CA: Jossey-Bass. 
Midwest County School District. (2014). Section III - The IEP process. Retrieved from https://www.ssdmo.org/cool_tools/inclusive/Resources/iep_process.pdf

Midwest County School District. (2017). Community based vocational instruction (CBVI) guidelines. Retrieved from https://www.ssdmo.org/cool_tools/inclusive/Resources/cbvi_guidelines.pd f

Midwest County School District. (2017). District overview. Retrieved from http://www.ssdmo.org/about_us/district_overview.html

Midwest County School District. (2017). Parent handbook - autism: resources, definition, and criteria. Retrieved from https://www.ssdmo.org/cool_tools/fcrc_parent_handbook/AutismPH.pdf

Miller-Warren, V. (2016). Parental insights on the effects of the secondary outcomes of graduates with disabilities. Rural Special Education Quarterly, 35(1), 31-36.

Missouri Department of Elementary and Secondary Education. (2014). MSIP 5: Comprehensive guide to the Missouri School Improvement Program. Retrieved from http://dese.mo.gov/sites/default/files/MSIP-5comprehensive-guide.pdf

Missouri Department of Elementary and Secondary Education. (2017). FAQs. Retrieved from: https://dese.mo.gov/faqs

Missouri Department of Elementary and Secondary Education. (2017). District report card [Data file]. Retrieved from https://mcds.dese.mo.gov/guidedinquiry/School\%20Report\%20Card/Distr 
ict\%20Report\%20Card.aspx\#Pec467b416c68400488f58d74ece3879f_2_8

$8 \mathrm{iT} 1$

Missouri Department of Elementary and Secondary Education. (2017). School report card [Data file]. Retrieved from https://mcds.dese.mo.gov/guidedinquiry/School\%20Report\%20Card/Scho ol\%20Report\%20Card.aspx?rp:SchoolYear=2016\&rp:SchoolYear=2015\& rp:SchoolYear=2014\&rp:SchoolYear=2013\&rp:DistrictCode=096119\#Pd 8aeaee456c84646ab8f737642d4b4ea_8_1205

Newman, L.A., Madaus, J.W., \& Javitz, H.S. (2016). Effect of transition planning on postsecondary support receipt by students with disabilities. Exceptional Children, 82(4), 497-514.

Northouse, P. (2016). Leadership: Theory and practice. (7th Ed.). Los Angeles, CA: Sage.

Owens, L.A. (2011). Self-determination in the employment first movement. National Gateway to Self-Determination, 2, 30-31. Retrieved from http://www.ngsd.org/.

Owusu-Bempah, J., Addison, R., \& Fairweather, J. (2011). Does follower subjectivity matter in defining authentic leadership? A call for qualitative research. Asia Pacific Journal of Business and Management, 2(2), 1-25.

Ozonoff, S., South, M., \& Miller, J.N. (2000). DSM-IV-defined Asperger syndrome: Cognitive, behavioral and early history differentiation from high-functioning autism. Autism, 4(1), 29-46.

Peacock, G., Amendah, D., Ouyang, L., \& Gross, S.D. (2012). Autism spectrum disorders and health care expenditures: The effects of co-occurring conditions. 
Journal of Developmental and Behavioral Pediatrics, 33, 2-8. http://dx.doi.org/10.1097/DBP.0b013e31823969de

Roux, A.M., Shattuck, P.T., Cooper, B.P., Anderson, K.A., Wagner, M., \& Narendorf, S.C. (2013). New research: Postsecondary employment experiences among young adults with an autism spectrum disorder. Journal of the American Academy of Child \& Adolescent Psychiatry, 52, 931-939. doi: 10.1016/j.jaac.2013.05.019

Saunders, B.S., Tilford, J.M., Fussell, J., Schulz, E.G., Casey, P.H., \& Kuo, D.Z. (2015). Financial and employment impact of intellectual disability on families of children with autism. Families, Systems, \& Health, 33(1), 36-45. http://dx/doi.org/10.1037.fsh0000102

Schall, C. \& McDonough, J.T. (2010). Autism spectrum disorders in adolescence and early adulthood: characteristics and issues. Journal of Vocational Rehabilitation, $32,81-88$.

Schall, C., Wehman, P., \& McDonough, J.L. (2012). Transition from school to work with students with autism spectrum disorders: understanding the process and achieving better outcomes. Pediatric Clinics of North America, 59, 189-202.

Schopler, E., Van Bourgondien, M.E., Wellman, G.J., \& Love, S.R. (2010). ( $2^{\text {nd }}$ Ed.). Childhood Autism Rating Scale. Los Angeles: Western Psychological Services. Shattuck, P. T., Narendorf, S. C., Cooper, B., Sterzing, P. R., Wagner, M., \& Taylor, J. L. (2012). Postsecondary education and employment among youth with an autism spectrum disorder. Pediatrics, 129(6), 1042-1049. 
Shekari, H. \& Nikooparvar, M. Z. (2012). Promoting leadership effectiveness in organizations: A case study on the involved factors of servant leadership. International Journal of Business Administration, 3(1), 54-65.

Smith, L. E., Maenner, M. J., \& Seltzer, M. M. (2012). Developmental trajectories in adolescents and adults with autism: The case of daily living skills. Journal of the American Academy of Child and Adolescent Psychiatry, 51(6), 622-631.

Taketa, K. (2017). Autism makes life after high school a struggle for 'the mayor of Parkway West'. St. Louis Post-Dispatch. Retrieved from http://www.stltoday.com/news/local/education/school-once-meant-isolation-nowan-autistic-graduate-is-the/article_9cb22a49-99c8-5ed8-a352-1881f2ec589c.html

Taylor, J.L, Smith, L.E., \& Mailick, M.R. (2014). Engagement in Vocational Activities Promotes Behavioral Development for Adults with Autism Spectrum Disorders. Journal of Autism and Developmental Disorders, 44(6), 1447-1460.

Taylor, J.L., \& Seltzer, M.M. (2011). Employment and post-secondary educational activities for young adults with autism spectrum disorders during the transition to adulthood. Journal of Autism and Developmental Disorders, 41, 566-574.

Tchaconas, A., \& Adesman, A., (2013). Autism spectrum disorders: A pediatric overview and update. Current Opinion in Pediatrics, 25(1), 130-144.

The Arc (2015). WIOA: What it means for people with intellectual and/or developmental disabilities. The Arc: National Policy Matters. Retrieved from: http://www.thearc.org/document.doc?id=5183 
Thomas, K. C., Ellis, A. R., McLaurin, C., Daniels, J., \& Morrissey, J. P. (2007). Access to care for autism-related services. Journal of Autism and Developmental Disorders, 37, 1902-1912.

Trainor, A. A., Morningstar, M. E., \& Murray, A. (2015). Characteristics of transition planning and services for students with high-incidence disabilities. Learning Disability Quarterly, 39(2), 113-124. https://doi.org/10.1177/0731948715607348

United States Department of Agriculture. (2016). National school lunch program. Retrieved from http://www.fns.usda.gov/nslp/national-school-lunch-program-nslp United States Department of Education (2011). Statement by Assistant Secretary Alexa Posny on the Fourth Annual World Autism Awareness Day. Retrieved from: www.ed.gov/news/press-releases/statement-assistant-secretary-alexa-posnyfourth-annual-world-autism-awareness-d.

United States Department of Health and Human Services, Health Resources and Services Administration, Maternal and Child Health Bureau. (2013). The National Survey of Children with Special Health Care Needs Chartbook 2009-2010. Rockville, MD: U.S. Department of Health and Human Services.

United States Department of Labor (2016). Office of disability employment policy: Monthly youth labor force participation rate and unemployment rate. Retrieved from: https://www.dol.gov/odep/stats/index.htm

Volkmar, F.R. (2017). Journal of Autism and Developmental Disorders. Retrieved from: http://www.springer.com/psychology/child+\%26+school+psychology/journal/108 03/PS2?detailsPage=aboutThis 
Walumbwa, F., Avolio, B., Gardner, W., Wernsing, T., \& Peterson, S. (2008). Authentic leadership: Development and validation of a theory-based measure. Journal of Management, 34(1), 89-126.

Wehman, P., Sima, A. P., Ketchum, J., West, M. D., Chan, F., \& Luecking, R. (2014). Predictors of successful transition from school to employment for youth with disabilities. Journal of Occupational Rehabilitation, 25(2), 323-334. https://doi.org/10.1007/s10926-014-9541- 


\section{Appendix A - Graduate Six Month Follow Up Questionnaire}

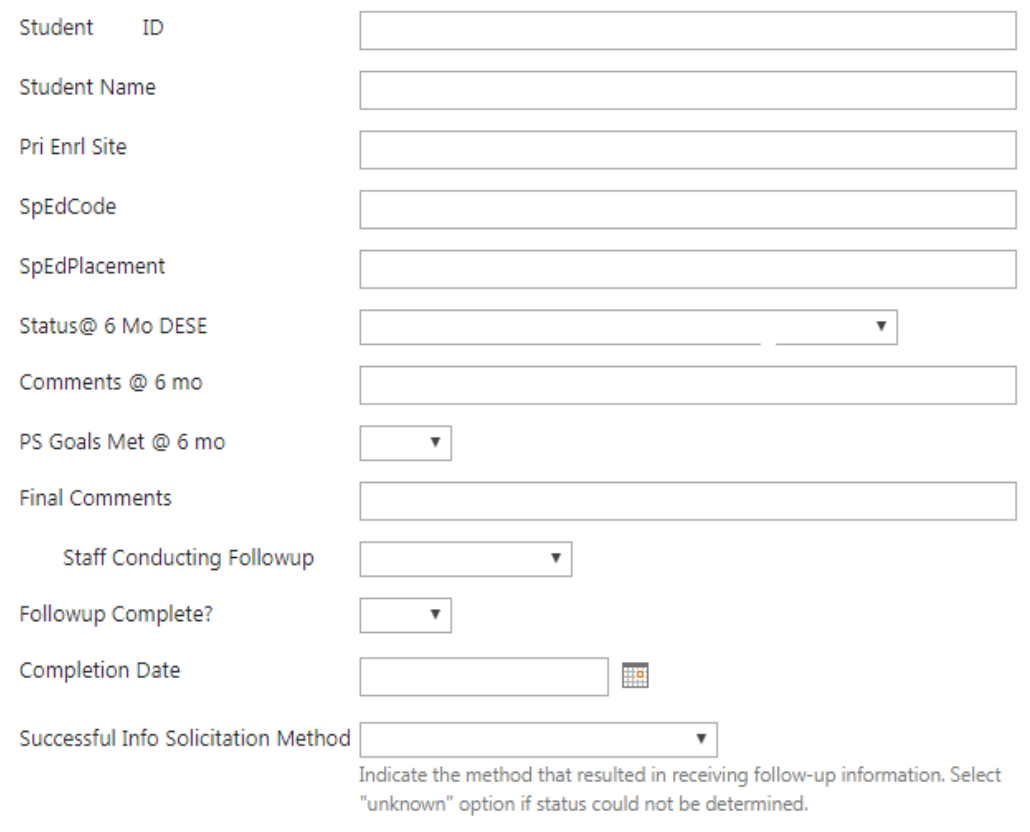




\section{Appendix B - Confirmation of Submission}

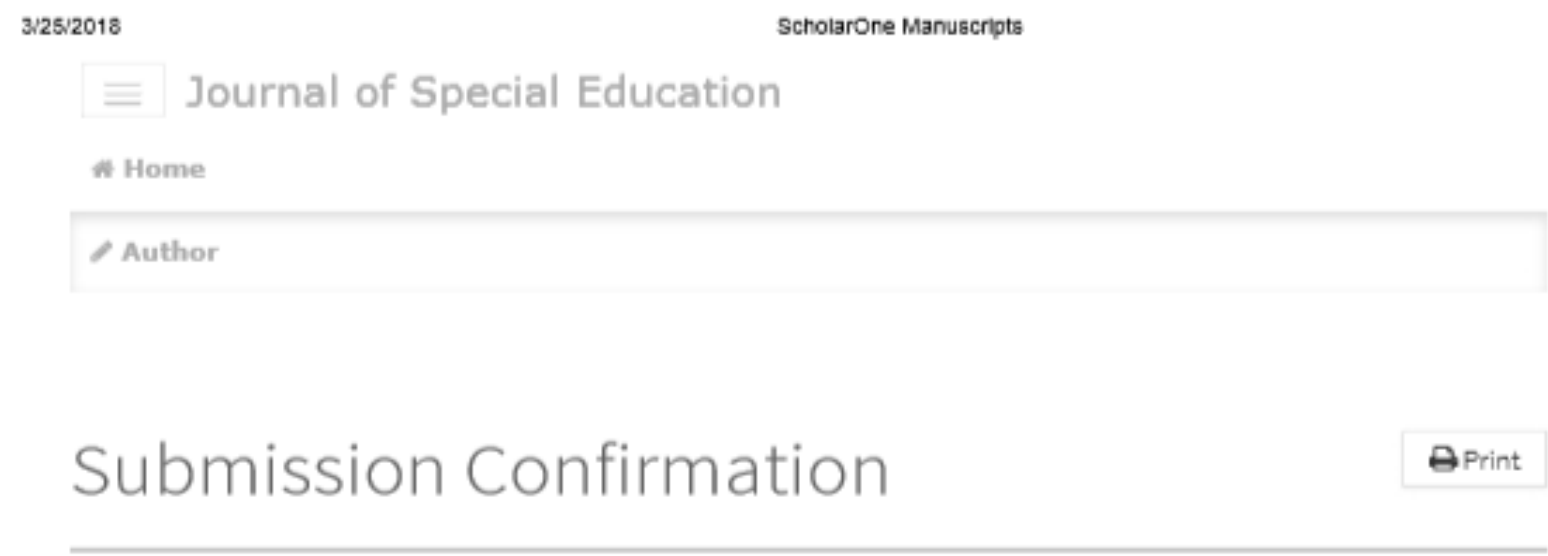

Thank you for your submission

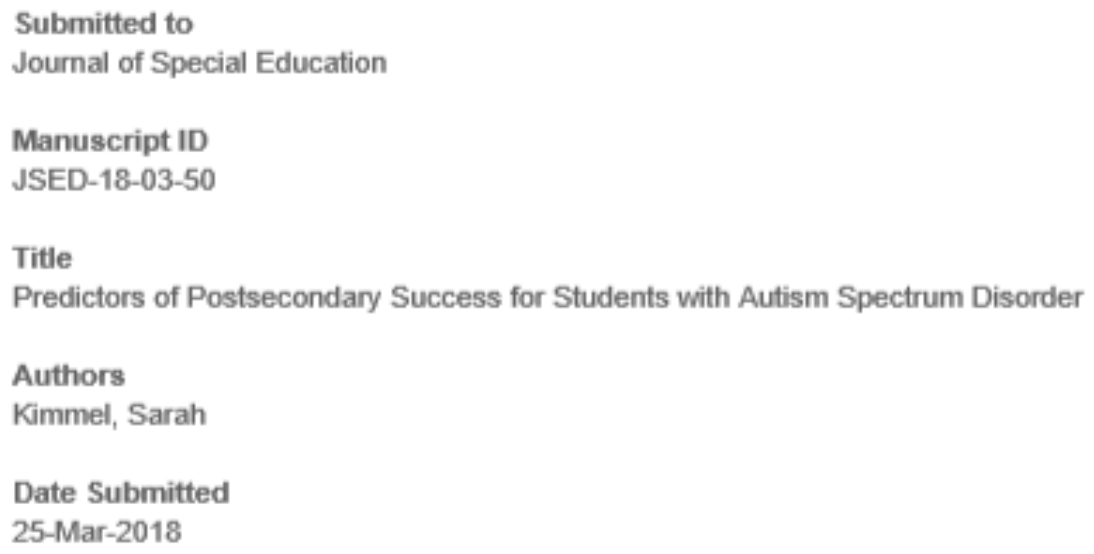

() Clarivate Analytics | () ScholarOne, Inc., 2018. All Rights Reserved. ScholarOne Manuscripts and ScholarOne are registered trademarks of ScholarOne, Inc. ScholarOne Manuscripts Patents \#7,257,767 and \#7,263,655.

* @ScholarOneNews | os System Requirements | @ Privacy Statement | $\star$ Terms of Use 


\section{VITA}

Sarah Elizabeth Kimmel was born in Kansas City, Missouri, where she remained until graduation from high school. She then attended Truman State University, in Kirksville, Missouri. While in Kirksville, Sarah earned a Bachelor's degree in Psychology in 2005. Immediately following graduation, Sarah returned to Kansas City and began her graduate education at the University of Missouri - Kansas City. While attending classes, Sarah worked as a women's shelter client advocate for Synergy Services in Parkville, Missouri. She earned a Master's degree in Counseling Psychology and Counselor Education in 2007 and an Education Specialist degree in School Counseling and Guidance in 2009. She completed her school counseling internship with North Kansas City School district at Maple Park Middle School and Oak Park High School.

Shortly after the completion of her degree in 2009, Sarah accepted a position with the Jefferson County Children's Division as a Foster Care and Adoption case manager and relocated to Saint Louis, Missouri. In 2010, she served as a family drug court case manager with the Family Resource Center in Jefferson County. During this time, she also obtained her License as a Professional Counselor.

In 2012, Sarah began working as a school counselor at the Special School District of Saint Louis County, serving students with disabilities in self-contained schools located in the northern region of St. Louis County. In 2016, she was offered a position within Special School District as a transition facilitator at a self-contained high school in the central area of St. Louis County. During her tenure, Sarah has had opportunities to serve in several leadership positions, including 2015-16 President of the Saint Louis County 
School Counselors Association, Transition Fair Chair Coordinator, and School

Leadership Team Member. In 2018, Sarah completed her Doctor of Education degree

through the University of Missouri in Columbia, Missouri. Sarah continues to work as a transition facilitator at Hiram Neuwoehner High School. She currently lives in Kirkwood, Missouri. 